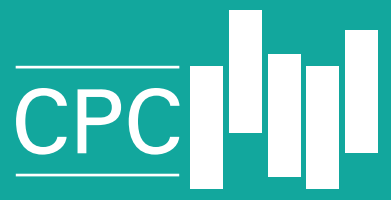

CENTRE FOR POPULATION CHANGE

\title{
When reality bites: \\ Local deaths and vaccine take-up
}

Corrado Giulietti

Michael Vlassopoulos

Yves Zenou 


\begin{abstract}
In this study, we investigate whether COVID-19 deaths that occurred before vaccination rollouts impact subsequent vaccination take-up. We use data on local vaccination rates and COVID-19-related deaths from England measured at high geographic granularity. We find that vaccination take-up as of November 2021 is positively associated with pre-vaccine COVID19-related deaths, controlling for demographic, economic, and health-related characteristics of the localities, while including geographic fixed effects. In addition, the share of ethnic minorities in a locality is negatively associated with vaccination rates, and localities with a larger share of ethnic minorities increase their vaccination rates if they are exposed to more COVID-related deaths. Further evidence on vaccination intention at the individual level from a representative sample corroborates these patterns. Overall, our evidence suggests that social proximity to victims of the disease triggers a desire to take protective measures against it.
\end{abstract}

\title{
KEYWORDS
}

Vaccination hesitancy, COVID-19, Social interactions, Information, Behaviour change.

\section{JEL CLASSIFICATION CODES}

$\mathrm{H} 51, \mathrm{I} 12$

\section{EDITORIAL NOTE}

Corrado Giulietti is Professor of Economics and Head of the Department of Economics within the School of Economic, Social and Political Sciences at the University of Southampton, where he is also member of the ESRC Centre for Population Change. Corrado is also member of the Global Labor Organization.

Michael Vlassopoulos is Professor of Economics at the University of Southampton and a member of the Institute of Labor Economics (IZA).

Yves Zenou is Professor of Economics at Monash University, Australia. Yves is a member of IZA and the Centre for Economic Policy Research (CEPR).

Corresponding author: Corrado Giulietti; c.giulietti@soton.ac.uk 
(c) Professor Corrado Giulietti, Professor Michael Vlassopoulos, Professor Yves Zenou all rights reserved. Short sections of text, not to exceed two paragraphs, may be quoted without explicit permission provided that full credit, including (c) notice, is given to the source.

The ESRC Centre for Population Change Working Paper Series is edited by Teresa McGowan.

\section{ESRC Centre for Population Change}

The ESRC Centre for Population Change (CPC) is a joint initiative between the Universities of Southampton, St Andrews, Edinburgh, Stirling, Strathclyde, in partnership with the Office for National Statistics (ONS) and the General Register Office Scotland (GROS). The Centre is funded by the Economic and Social Research Council (ESRC) grant numbers RES-625-28-0001, ES/K007394/1 and ES/R009139/1.

This working paper series publishes independent research, not always funded through the Centre. The views and opinions expressed by authors do not necessarily reflect those of the CPC, ESRC, ONS or NRS.

\section{Website $\mid$ Email $\mid$ Twitter $\mid$ Facebook $\mid$ Mendeley}




\section{WHEN REALITY BITES: \\ LOCAL DEATHS AND VACCINE TAKE-UP}

\section{TABLE OF CONTENTS}

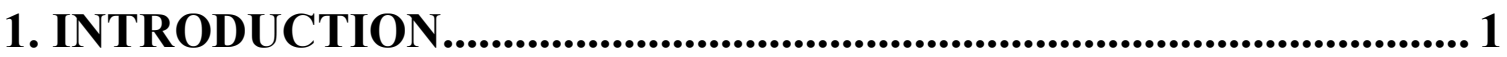

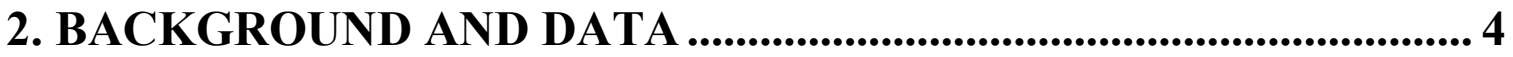

2.1 COVID-19 PANDEMIC AND VACCINATION ROLLOUT IN THE

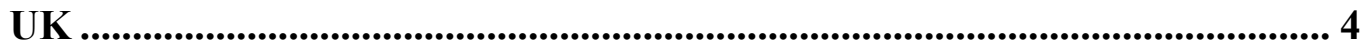

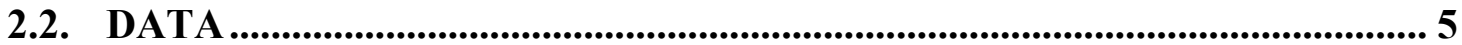

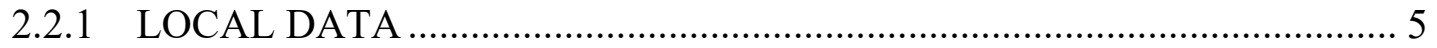

2.2.3 INDIVIDUAL DATA .............................................................................. 6

3. EMPIRICAL METHOD ....................................................................... 7

4. LOCALITY LEVEL EVIDENCE .....................................................9

4.1 MAIN RESULTS ............................................................................................ 9

4.1.1 SHARE OF ETHNIC MINORITIES ………………………………...... 9

4.1.2 SIZE OF LOCAL DEATH RATE........................................................... 10

4.1.3 TIMING ………………………………………………………. 12

4.2 ROBUSTNESS AND PLACEBO TESTS ……........................................ 13

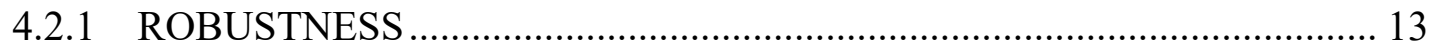

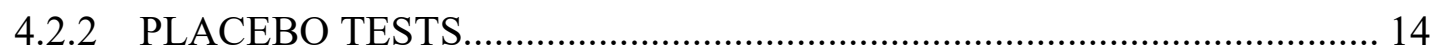

5. INDIVIDUAL LEVEL EVIDENCE ................................................ 15

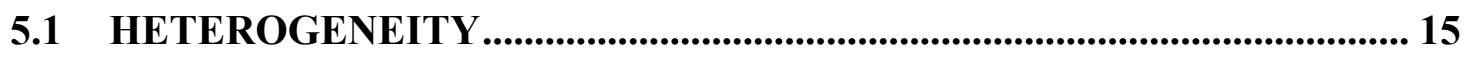

5.2 ADDITIONAL RESULTS ON ETHNIC MINORITIES .............................. 16

6. CONCEPTUAL FRAMEWORK.................................................... 18

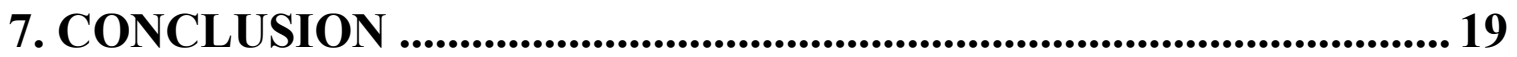

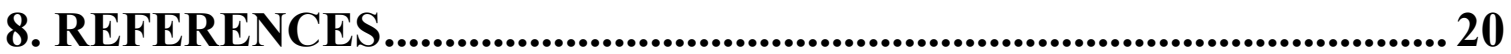




\section{INTRODUCTION}

"If I had the information I have today, we would have gotten vaccinated."

New York Times, July30th 2021

(https://www.nytimes.com/2021/07/30/us/covid-vaccine-hesitancy-regret.html)

In various situations, individuals make binary choices, in which the benefits and costs are not perfectly known, while being also influenced by social interactions. For instance, the decisions to engage in risky health behaviour (Cawley \& Ruhm, 2011; Hsieh \& van Kippersluis, 2018), to commit crime (Becker, 1968; Damm \& Dustmann, 2014), to adopt an agricultural technology (Bandiera \& Rasul, 2006; Conley \& Udry, 2010; Islam et al., 2018), to migrate (Borjas, 1999; Munshi, 2003), to participate in a retirement or other social program (Duflo \& Saez, 2003, Dahl et al., 2014) are made without fully knowing the benefits or costs of these choices and are heavily affected by others' decisions. In these environments, a "local shock" that reveals information about the benefits or costs of the binary choice at hand may trigger agents to make a decision.

In this study, we focus on the decision to participate in the COVID-19 vaccination program. We examine whether a local shock, that is, the rate of COVID-19 deaths in one's local area, that reveals information about the disease severity impacts vaccination take-up. COVID-19 vaccination decisions offer a uniquely suitable setting to study the extent to which people change their decisions related to a high-stakes issue when facing hard facts. First, these decisions have serious consequences for decision-makers, as they concern a new and highly infectious virus with a non-negligible risk of hospitalization or death and unknown long-term effects. Second, the World Health Organization has identified persistent vaccine hesitancy as a major public health issue ${ }^{1}$. It is well documented that, even in countries where the vaccine is widely available at no cost, there is imperfect take-up ${ }^{2}$. Vaccine hesitancy has been attributed to various factors, including low perceptions of health risks associated with the virus or concerns about side effects of the rapidly developed vaccine (Robertson et al., 2021; Razai et al., 2021; Allington et al., 2021). Often, these beliefs are fuelled by misinformation around

\footnotetext{
${ }^{1}$ See; https://www.who.int/news-room/spotlight/ten-threats-to-global-health-in-2019

${ }^{2}$ See; https://ourworldindata.org/covid-vaccinations
} 
COVID-19 that circulates abundantly in the social media or through one's social networks and which undermines trust toward health authorities and science.

What information would convince COVID-19 sceptics to vaccinate? If the processing of the evidence is distorted by (mis)information that confirms one's beliefs while suppressing information that contradicts them (Epley \& Gilovich, 2016), then it is unlikely that scientific facts will be very effective. By contrast, one might expect that sceptics or hesitants would be alarmed if they receive news through their social networks that people close to them fall ill seriously or die from the disease. This type of hard evidence is more likely to lead sceptics to change their mind and vaccinate. A similar phenomenon was observed during the AIDS pandemic where behaviours that prevented transmission where more likely to be adopted in areas with higher prevalence of cases (Ahituv et al., 1996) and when one knew someone who had died of AIDS (Macintyre et al., 2001). Although various anecdotal media reports during the COVID-19 pandemic corroborate the view that close exposure to victims changes attitudes toward vaccination ${ }^{3}$, to the best of our knowledge the issue has not received systematic empirical scrutiny.

In this study, we deploy various data sources from England to explore this issue. We use spatial data on vaccination take-ups and COVID-19-related deaths measured at an unusually high geographic granularity and document several interesting patterns. First, cumulative vaccination take-up as of November 2021 is positively associated with COVID-19related deaths that occurred before the vaccination program's rollouts. This is true controlling for demographic, economic, and health related (e.g., mortality rates and flu vaccination coverage) features of the localities and geographic fixed effects at a higher level of disaggregation than our main spatial unit of analysis which is the neighbourhood. A set of placebo tests provides support for our identifying assumption that COVID-19 related mortality is conditionally exogenous.

Then, we investigate whether social proximity to victims underpins the impact of mortality on vaccination. Indeed, Funk et al. (2009) showed that social networks can suppress

\footnotetext{
${ }^{3}$ For instance, the quote in the epigraph is from a New York Times article reporting on a couple who had refused to get vaccinated until the husband caught the virus and was fighting for his life. Similar stories have been reported in the UK (https://www.theguardian.com/world/2021/jul/26/covid-patients-tell-of-regrets-overrefusing- jab-vaccine-intensive-care) and Australia (https:/www.theage.com.au/national/victoria/leon-stingaswon-t-be-there-to- pick-the-veggies-he-planted-just-weeks-ago-20210930-p58w1u.html).
} 
the spreading of a contagious disease by raising awareness and promoting protective behaviour. To examine this, we ask whether members of ethnic minority groups who are, on average, more vaccine hesitant are swayed more strongly by information about deaths that occur in their local area. We expect this to be the case because ethnic minorities are close-knit communities in which social cohesion and network ties tend to be stronger compared to those among the white majority (Battu et al., 2011; Patacchini \& Zenou, 2012; Eubank, 2019; Marte'n et al., 2019). Thus, the information about a community member's death is more likely to circulate more quickly and efficiently among ethnic communities ${ }^{4}$. That is, ethnic minorities who live in localities with higher presence of own-ethnicity people are more likely to be exposed to news about a COVID-19-related death that has occurred within their community.

We find that the share of ethnic minorities in a locality is negatively associated with vaccination rates. Indeed, localities with large share of ethnic minorities increase their vaccination rates as they get more exposed to COVID related deaths. In particular, we estimate that the interquartile change in death rates (which corresponds to a change of 7 deaths within a Middle Layer Super Output Area (MSOA)) leads to about 1 percentage point change in vaccination rates (corresponding to about 82 vaccinations per MSOA) in localities with a high presence of ethnic minorities ( $60 \%$ or greater). We also find that larger death rate shocks - in the top tercile of the distribution-have stronger effects on vaccination rates. Our results are robust to a battery of sensitivity and robustness checks where we consider alternative functional forms, definitions of ethnicity, and measures of vaccinations and COVID-19 deaths.

We buttress this analysis with evidence on vaccination intention at the individual level using a nationally representative survey of the UK population. The survey collected information about the vaccination intentions of participants in November 2020 (before the vaccination rollout), which we exploit in this part of our analysis. The results corroborate the findings from the local-level analysis that members of ethnic minorities are less likely to vaccinate and that the gap in willingness to vaccinate between whites and ethnic minorities closes as the death rate in the locality where they live increases. We can also explore further heterogeneity analysis of the positive interaction effect between ethnic minority and death rate. In particular, we find that the effect is driven by members of the ethnic minority aged below

\footnotetext{
${ }^{4}$ Some evidence about social interactions being more intensive for ethnic minorities is presented in Table A9. In the Table, we use statistics from Waves 3 and 6 of Understanding Society to show that ethnic minorities are more likely to engage in activities and discuss issues with their close network of friends.
} 
50 and those ethnic groups that display a lower intention to vaccinate. We also find that the effect is more pronounced for ethnic minorities embedded in a larger local network of coethnics. This is consistent with the idea that closer proximity to someone who has died from COVID-19 increases the probability of vaccinating.

This study is related to the literature on the determinants of vaccination take-up, which has examined several factors that we review here very selectively. Probably, the closest studies to ours are that of Philipson (1996) and Oster (2018) who find that childhood disease prevalence and outbreaks increase vaccination rates in the US. Some studies have shown that the spreading of information that discredits vaccines by politically motivated entities or the mass media can affect immunization rates (Chang, 2018; Loomba et al., 2021; Carrieri et al., 2019; Qian et al., 2020; Martinez-Bravo \& Stegmann, 2021; Hansen \& Schmidtblaicher, 2021). More specific to the COVID-19 context, vaccination take-up has been shown to vary by various socioeconomic and demographic characteristics (Robinson et al., 2020) and has been linked to traits such as individualism (Bian et al., 2021), and psychological characteristics (Murphy et al., 2021). In a cross-country analysis, Auld \& Toxvaerd (2021) found that initial vaccination rates are not associated with total COVID-19 deaths on the eve of the rollout. To the best of our knowledge, ours is the first study to examine the impact of COVID-19 mortality on vaccination at the local level and to provide suggestive evidence of the underlying channel.

\section{BACKGROUND AND DATA}

\subsection{COVID-19 PANDEMIC AND VACCINATION ROLLOUT IN THE UK}

In this section, we provide a brief timeline of the COVID-19 pandemic and vaccination rollout in the UK.

The first UK COVID-19 cases were recorded in late January 2020, while the first fatality occurred in early March 2020. Soon after, the government announced a national lockdown. In early April 2020, at the peak of the first wave of the pandemic, the country was recording more than 1000 daily deaths. By the end of November 2020, the UK had recorded more than 60 thousand deaths related to COVID-19. 
The UK was the first country to approve a COVID-19 vaccine in early December 2020; the vaccination program began on 8 December. The vaccine was offered at vaccination centres and pharmacies, and appointments could be made online or through a GP surgery, so vaccines were widely available, and access was reasonably easy. The rollout proceeded in two main phases: in phase one, which was concluded in mid-April 2021, vulnerable groups were prioritized, that is, people above 50 in a staggered way starting from the most senior ones (above 80), frontline health and social care workers, and individuals with underlying health conditions (about 31.8 million). A total of 32.5 million individuals had received a first dose by the end of the first phase (15 April 2021). In the second phase, the vaccine was made available to younger age groups (about 21 million) in a staggered way, so that the vaccine was offered to all adults in the UK by the end of July 2021. On 1 November, 2021, the total number of individuals that had received the first dose surpassed the 50 million mark, amounting to $87 \%$ of the population aged 12 and over (https://coronavirus.data.gov.uk/details/vaccinations).

\subsection{DATA}

\subsubsection{LOCAL DATA}

For the local-level analysis, we gathered data at the Middle Super Output Area (MSOA) level for England from various sources. MSOA is a small geographic area with an average population of about 8,000. MSOAs are quite uniform regarding population size, making them ideal for a local-level analysis. A map of MSOAs of England is presented in Figure A4 in Appendix A; key features of MSOAs are reported in Table A1. Table A2 contains data sources and links for all variables used in the local-level analysis.

Our main outcome for the local-level analysis is the vaccination rate, defined as the cumulative number of first dose vaccinations between 8 December, 2020, and 25 November, 2021, divided by the total population in the MSOA. The two key explanatory variables are the ethnic share and the COVID-19 death rate. Ethnic share is the fraction of ethnic minorities in the MSOA population. Ethnic minorities are defined as persons who report ethnicity different than white. The COVID-19 death rate is defined as the cumulative count of deaths from COVID-19 between March and November 2020 over total population in the MSOA. Notably, 
data on vaccinations and COVID-19 deaths — at this granular level—are not available by ethnicity ${ }^{5}$.

We present summary statistics of the MSOA-level data in Table A3 in Appendix A. As of 25 November, 2021, the vaccination rate was $75.2 \%$. The COVID-19 death rate was 0.001 ; a comparison with deaths for all other causes (0.007) provides an immediate measure of the relatively large impact that COVID-19 had at the local level for just nine months. The data show, that on average, one out of seven persons in each MSOA belongs to an ethnic minority. The Table also contains summary statistics of the other variables used in the analysis.

\subsubsection{INDIVIDUAL DATA}

For the individual-level analysis, we accessed data on the safeguarded version of the Understanding Society COVID-19 survey, a special survey that explores individuals' experiences during the COVID-19 pandemic (University of Essex. ISER, 2021). The survey was conducted monthly starting from April 2020 until July 2020, and every other month from September onward.

Our analysis focuses on the question about vaccination intentions asked in the November 2020 wave: "Imagine that a vaccine against COVID-19 was available for anyone who wanted it. How likely or unlikely would you be to take the vaccine?" This question was answered on a four-item scale (Very likely, Likely, Unlikely, Very unlikely). Note that this question was asked at a time when a clear plan about vaccinations did not yet exist $^{6}$. Our outcome of interest is vaccine intention, defined as a binary variable equal to 1 if the answer to the vaccination intentions were "Very Likely" or "Likely" and 0 otherwise. In additional results, we also used data on actual vaccinations obtained from the March 2021 wave. We defined a dummy variable for vaccinations based on the question "Have you had a coronavirus vaccination?" with answers "Yes, first vaccination only," "Yes, both vaccinations," and "No, but I have an appointment" coded as 1 and 0 otherwise $^{7}$.

\footnotetext{
${ }^{5}$ Data on vaccinations by ethnicity are only available at the regional level; deaths from COVID-19 by ethnicity are only available at the country level.

${ }^{6}$ Note that questions on vaccination intentions are also asked in the waves of January 2021 and March 2021 of the Understanding Society COVID-19 survey. We do not use data from these waves because vaccination intentions could be influenced by actual vaccine behaviour, potentially confounding the impact of the local shock.

${ }^{7}$ Note that at the time of the survey (March 2020), vaccinations were available mainly for individuals aged 50 and above.
} 


\section{EMPIRICAL METHOD}

We are interested in estimating the relationship between vaccination rates and COVID-19related deaths within localities (MSOAs). Our specification takes the form:

$Y \boldsymbol{l}=\beta 0+\beta 1$ CovidDeath $\boldsymbol{l}+X \boldsymbol{l} \gamma+L A D+E \boldsymbol{l}$

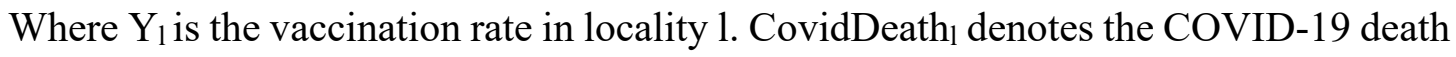
rate, which corresponds to the ratio between the number of deaths related to COVID in locality 1 and the population in the area. $X_{1}$ is a vector of controls at the locality level (non-Covid death rate, age shares, ethnic shares, deprivation index, etc.), LAD are local authority district fixed effects, and $\mathrm{E}_{1}$ is the error term ${ }^{8}$.

Our analysis relies on cross-sectional variation for identification. The main threat for causal interpretation of the main parameter $\beta_{1}$ is reverse causality, as it may well be that vaccination rates are driving COVID-19 related deaths when the two are measured contemporaneously. To overcome this issue, we use deaths that occurred before vaccines were rolled out, that is, deaths that occurred between March and November 2020. A second concern is the possible presence of unobservable area characteristics or shocks that might be confounding our estimates of the effect of deaths on vaccination rates. To address this, we use a range of locality-level characteristics including demographic structure and socio-economic deprivation, alongside measures of health status (mortality rate) and of the demand for preventive care (flu vaccination coverage). Thus, our identifying assumption is that, conditional on the rich set of controls included in $\mathrm{X}_{1}$ and the local authority fixed effects, COVID-19 related deaths are quasi-randomly assigned across localities. Figure A2 in the Appendix shows the distribution of the residualized COVID death rate, that is, the residuals obtained from a regression of the death rate on all other covariates of the regression in Table 1 Column I, including the LAD fixed effects. The figure illustrates that, after removing the impact of these observables, the distribution of death still exhibits a fair amount of variation and that such variation is close to that of a normal distribution.

\footnotetext{
${ }^{8}$ Local Authority Districts (LADs) are administrative entities (there are 307 in England) that are supersets of MSOAs. The median number of MSOAs per LAD is 26. See Table A1 in Appendix A for further statistics. We used LAD indicators in our regressions to account for all unobservable factors at this level that might affect vaccinations in each MSOA.
} 
As a check of our identification, we performed two placebo tests. The first follows a randomization-based inference procedure where we randomly reassigned to each locality the death rate of a neighbouring locality. This exercise, reported in Section 4.2, indicates that our results are "extreme/unusual" with respect to a distribution of coefficients generated by chance, providing support for the causal interpretation of our results. The second is a falsification test, in which we check whether COVID-19 related deaths explain preventive health behaviour that occurred ahead of the pandemic. Specifically, we estimated Equation (1) on the fraction of women aged 25-49 who underwent cervical screening out of eligible women in the MSOA and on the vaccination rate related to three different child immunization programmes. We find that COVID-19-deaths have no statistically significant association with these outcomes.

To examine whether there is heterogeneity in the impact of COVID deaths related to the concentration of ethnic minority groups in an area, we estimate an augmented specification, which includes an interaction between the COVID-19-death rate and the share of ethnic minorities $\operatorname{Min}_{I}$ in a locality:

$Y \boldsymbol{l}=\beta 0+\beta 1$ CovidDeath $\boldsymbol{l}+\beta 2$ MinShare $\boldsymbol{l}+\beta 3($ CovidDeath $\boldsymbol{l} \times$ MinShare $\boldsymbol{l})+X \boldsymbol{l} \gamma+L A D+E \boldsymbol{l}$

The main parameter of interest is $\beta 3$, which tells us whether localities with higher presence of ethnic minority groups respond to local death rate differently. To avoid a bias that arises from the fact that the share of ethnic minority might be correlated with unobserved area characteristics, we use the ethnic composition of localities measured ten years earlier. Figure A1 in Appendix A shows that there is no systematic relationship between share of ethnic minority and COVID-19-related deaths at the MSOA-level.

When using individual data, we estimate the following specification:

$Y_{\boldsymbol{i}}=\beta 0+\beta 1$ CovidDeath $\boldsymbol{l}+\beta 2 M i n \boldsymbol{i}+\beta 3($ CovidDeath $\boldsymbol{l} \times$ Mini $)+Z \boldsymbol{i} \delta+X \boldsymbol{l} \gamma+L A D+E \boldsymbol{i}$

Where $\mathrm{Y}_{\mathrm{i}}$ is an indicator denoting whether individual $\mathrm{i}$ has expressed an intention of receiving the vaccine. $\mathrm{Min}_{\mathrm{i}}$ is an indicator denoting whether individual $\mathrm{i}$ belongs to an ethnic minority. $Z_{\mathrm{i}}$ is a vector of controls at the individual level (gender, age, education, health status, marital status, etc.), while $\mathrm{X}_{1}$ are locality-level controls as in Equation (1). We cluster standard errors at the MSOA level, which is the level at which death rates are measured. The main parameter of interest here is $\beta 3$, which reveals whether ethnic minorities' willingness to vaccinate is affected differently by deaths than that of whites. 


\section{LOCALITY LEVEL EVIDENCE}

\subsection{MAIN RESULTS}

We present our primary results in Table 1 based on the estimations of equations (1) and (2) in which the outcome of interest is the vaccination rate at the MSOA level. The first result that emerges in Column I is that a positive and statistically significant relationship exists between death rates and vaccination rates $(\mathrm{p}<0.01)$. This suggests that people are affected by deaths that occur near them when deciding to vaccinate. Regarding magnitude, a one standard deviation increase in the death rate ( 0.1 percentage points or about 8 people) is associated with an increase in the vaccination rate by about 0.25 percentage points or about 21 additional vaccinations. Second, we observe that localities with higher share of ethnic minorities have a lower vaccination rate $(\mathrm{p}<0.01)$, a pattern that has also been documented elsewhere (Razai et al., 2021; Robertson et al., 2021) ${ }^{9}$. In particular, a 10 percentage point increase in the share of ethnic minority in a locality is associated with about 0.5 percentage point reduction in the vaccination rate. For the other predictors of COVID-19 vaccination, we find them to have the expected signs and to be statistically significant: higher shares of older groups are associated with more vaccination, and more deprived areas experience less vaccination, while areas with higher flu vaccination coverage have also higher vaccination rates. However, we find that the death rate due to causes unrelated to COVID-19 lack a statistically significant association with COVID-19 vaccination rates.

\subsubsection{SHARE OF ETHNIC MINORITIES}

In the second column, we examine the heterogeneity of the impact of the death rate with respect to the size of the ethnic minority groups. We find that the interaction term is positive and statistically significant, indicating that the impact of death rates on vaccination is larger in localities with higher share of ethnic minority groups. A very similar effect is obtained in Column III where, instead of controlling for non-COVID-related deaths during the pandemic, we control for the pre-pandemic mortality rate. Figure A5 in Appendix A offers a visual quantification of this effect: the two lines trace out the predicted vaccination rate (obtained from the estimates in Column II) as a function of the share of ethnic minority for death rates at the 25 th and 75 th percentiles of the distribution, respectively. We observe that, in localities

\footnotetext{
${ }^{9}$ In the UK, ethnic minorities have been disproportionately affected by the COVID-19 pandemic both in terms of hospitalizations and deaths as well as economically (Platt \& Warwick, 2020).
} 
with a high presence of ethnic minorities, say at $60 \%$, the interquartile change in death rates leads to about 1 percentage point change in vaccination rates (corresponding to about 82 vaccinations per MSOA). We postulate that the reasons behind the stronger reaction to deaths by ethnic minorities are twofold: first, the fact that they are, on average, more hesitant than whites makes it easier to detect an effect, and, second, they have tighter social networks through which dramatic news such as the passing of a co-ethnic travel quickly. We provide suggestive evidence in support of the network channel using the individual-level data in Section 5.

\subsubsection{SIZE OF LOCAL DEATH RATE}

One might expect that the impact of the mortality rate on vaccination is larger in areas that have experienced a heavier burden of deaths. In Table 2, we explore such heterogeneity. Columns I and II contain results of the same specification as in the respective columns of Table 1 using dummies for the terciles of the COVID-19 death rate distribution instead of a linear term. We find that the localities that experienced death rate in the highest tercile are associated with an increase in vaccination rate of 0.4 percentage points relative to localities in the lowest tercile $(\mathrm{p}<0.05)$. Furthermore, for the share of ethnic minority gradient, we observe that a differential positive effect exists only in localities experiencing a death rate in the third tercile $(p<0.01)$. In the last two columns, we then split the sample into MSOAs with share of ethnic minority below (Column III) and above (Column IV) the median value, respectively. The results reveal that the positive effect of the share of ethnic minority in the MSOAs experiencing high deaths ( 3 rd tercile) is present only in localities with above median share of ethnic minority $(p<0.01)$. This analysis thus indicates that the simultaneous presence of a high death rate and a large ethnic community in an area induce a stronger positive relationship between COVID-19 mortality and vaccinations. 


\begin{tabular}{|c|c|c|c|}
\hline & 1 & 2 & 3 \\
\hline \multirow[t]{3}{*}{ COVID-19 DeathRate } & $2.477^{* * *}$ & $2.556^{* * *}$ & $2.183^{* *}$ \\
\hline & $(.845)$ & $(.884)$ & $(.908)$ \\
\hline & {$[.021]$} & {$[.021]$} & {$[.018]$} \\
\hline \multirow[t]{3}{*}{ Share of Ethnic Minority } & $-.048^{* * *}$ & $-.054^{* * *}$ & $-.053^{* * *}$ \\
\hline & $(.008)$ & $(.008)$ & $(.008)$ \\
\hline & {$[-.098]$} & {$[-.109]$} & {$[-.108]$} \\
\hline \multirow[t]{3}{*}{ COVID-19 Deaths $\times$ Share of Ethnic Minority } & & $18.210^{* * *}$ & $18.335^{* * *}$ \\
\hline & & $(6.545)$ & $(6.545)$ \\
\hline & & {$[.026]$} & {$[.026]$} \\
\hline \multirow[t]{2}{*}{ \% Aged 16-29 } & $.169^{* * *}$ & $.178^{* * *}$ & $.175^{* * *}$ \\
\hline & $(.035)$ & $(.035)$ & $(.035)$ \\
\hline \multirow[t]{2}{*}{$\%$ Aged $30-49$} & $.296^{* * *}$ & $.304^{* * *}$ & $.299^{* * *}$ \\
\hline & $(.059)$ & $(.058)$ & $(.059)$ \\
\hline \multirow[t]{2}{*}{$\%$ Aged 50-64 } & $.704^{* * *}$ & $.702^{* * *}$ & $.698^{* * *}$ \\
\hline & $(.058)$ & $(.058)$ & $(.059)$ \\
\hline \multirow[t]{2}{*}{ \% Aged 65-79 } & $.741^{* * *}$ & $.746^{* * *}$ & $.745^{* * *}$ \\
\hline & $(.044)$ & $(.044)$ & $(.044)$ \\
\hline \multirow[t]{2}{*}{$\%$ Aged $80+$} & $.121^{*}$ & $.130^{*}$ & .091 \\
\hline & $(.067)$ & $(.067)$ & $(.072)$ \\
\hline \multirow[t]{2}{*}{ Index of Multiple Deprivation } & $-.227^{* * *}$ & $-.227^{* * *}$ & $-.230^{* * *}$ \\
\hline & $(.008)$ & $(.008)$ & $(.009)$ \\
\hline \multirow[t]{2}{*}{ Seasonal Flu Vaccination Rate } & $.255^{* * *}$ & $.255^{* * *}$ & $.255^{* * *}$ \\
\hline & $(.029)$ & $(.029)$ & $(.029)$ \\
\hline \multirow[t]{2}{*}{ Non-COVIDDeathRate } & .375 & .421 & \\
\hline & $(.369)$ & $(.368)$ & \\
\hline \multirow[t]{2}{*}{ 2015-2019 Death Rate } & & & $.865^{*}$ \\
\hline & & & $(.462)$ \\
\hline Local Authority District Fixed Effects & Yes & Yes & Yes \\
\hline $\mathrm{N}$ & 6,789 & 6,789 & 6,789 \\
\hline$R^{2}$ & .76 & .76 & .76 \\
\hline
\end{tabular}

Table 1: COVID-19 deaths and vaccination rate

Notes: Robust standard errors in parentheses. Standardized coefficients are presented in square brackets. The variables for the main effects of the interactions have been re-centered; hence, the coefficients refer to their mean value.

The dependent variable is vaccination rate in the Middle Super Output Area (MSOA), defined as the cumulative number of first dose vaccinations between 8th December 2020 to 25th November 2021 divided by total population in the MSOA.

COVID-19 Death Rate is defined as the cumulative number of COVID-19 deaths between 1st March 2020 and 30th November 2020 in the MSOA divided by total population in the MSOA.

Non-COVID Death Rate is defined as the cumulative number of deaths not related to COVID between 1st March 2020 and 30th November 2020 in the MSOA divided by total population in the MSOA.

2015-2019 Death Rate is defined as the average yearly death rate from all causes between January 2015 and December 2019 in the MSOA divided by total population in the MSOA.

The age variable represents the \% of each group in the MSOA population. The Index of Multiple Deprivation is the score divided by 100 .

$* \mathrm{p}<0.10 ; * * \mathrm{p}<0.05 . ; * * * \mathrm{p}<0.01$ 


\begin{tabular}{|c|c|c|c|c|}
\hline & 1 & 2 & 3 & 4 \\
\hline \multirow[t]{3}{*}{ Share of Ethnic Minority } & $-.048^{* * *}$ & $-.066^{* * *}$ & $-.210^{*}$ & $-.047^{* * *}$ \\
\hline & $(.008)$ & $(.011)$ & $(.111)$ & $(.014)$ \\
\hline & {$[-.098]$} & {$[-.135]$} & {$[-.039]$} & {$[-.106]$} \\
\hline \multirow[t]{3}{*}{$2^{\text {nd }}$ Tercile COVID-19 Deaths } & .001 & .001 & .006 & -.003 \\
\hline & $(.002)$ & $(.002)$ & $(.014)$ & $(.003)$ \\
\hline & {$[.004]$} & {$[.005]$} & {$[.046]$} & {$[-.017]$} \\
\hline \multirow[t]{3}{*}{$3^{\text {rd }}$ Tercile COVID-19 Deaths } & $.004^{* *}$ & $.004^{* *}$ & -.008 & $-.006^{*}$ \\
\hline & $(.002)$ & $(.002)$ & $(.015)$ & $(.003)$ \\
\hline & {$[.022]$} & {$[.021]$} & {$[-.058]$} & {$[-.031]$} \\
\hline \multirow[t]{3}{*}{$2^{\text {nd }}$ Tercile COVID-19 Deaths $\times$ Share of Ethnic Minority } & & .004 & .040 & .013 \\
\hline & & $(.010)$ & $(.124)$ & $(.013)$ \\
\hline & & {$[.004]$} & {$[.033]$} & {$[.019]$} \\
\hline \multirow[t]{3}{*}{$3^{\text {rd }}$ Tercile COVID-19 Deaths $\times$ Share of Ethnic Minority } & & $.032^{* * *}$ & -.109 & $.054^{* * *}$ \\
\hline & & $(.011)$ & $(.135)$ & $(.014)$ \\
\hline & & {$[.041]$} & {$[-.091]$} & {$[.087]$} \\
\hline $\mathrm{N}$ & 6,789 & 6,789 & 3,395 & 3,394 \\
\hline$R^{2}$ & .76 & .76 & .71 & .72 \\
\hline
\end{tabular}

Table 2: Size of the local shock

Notes: R Robust standard errors in parentheses. Standardized coefficients are presented in square brackets. The variables for the main effects of the interactions have been re-centered; hence, the coefficients refer to their mean value.

Columns I and II are the same specification of the corresponding models in Table 1 using tercile of COVID-19 Death Rate instead of the continuous variable.

Columns III and IV are the same specification of Column I but on the subsets of MSOA with Share of Ethnic Minority below (Column III) and above (III) the median value.

$* \mathrm{p}<0.10 . ; \quad * * \mathrm{p}<0.05 . ; \quad * * * \mathrm{p}<0.01$

\subsubsection{TIMING}

To examine what happens when younger cohorts become eligible, we exploit the fact that the vaccination program was rolled-out in phases, prioritizing older age groups first. In particular, we partitioned the period of the vaccination campaign that we examine - starting in December 2020 and ending in November 2021 - to four phases that corresponded to when the vaccine became available to different age groups: for 70+ (8th Dec to 15th Feb); for 50+ (16th Feb to 25th April); for 30+ (26th April to 18th June); and for 18+(19th June to 25th November). This analysis is presented in Figure 1, which plots the coefficient and the confidence interval of the interaction between share of ethnic minority and death rate that we obtain from estimating Equation (2) for the whole period and for each of the 4 sub-periods separately. The pattern that emerges is that the $70+$ cohort is inelastic with respect to the death rate, which was what we 
might expect from the group that is the most vulnerable in the population. The younger cohorts show similar positive reaction to the death rate, with the 50 to 70 group showing a slightly larger and more precisely estimated response than the two remaining younger cohorts, though the coefficients are not statistically distinguishable.

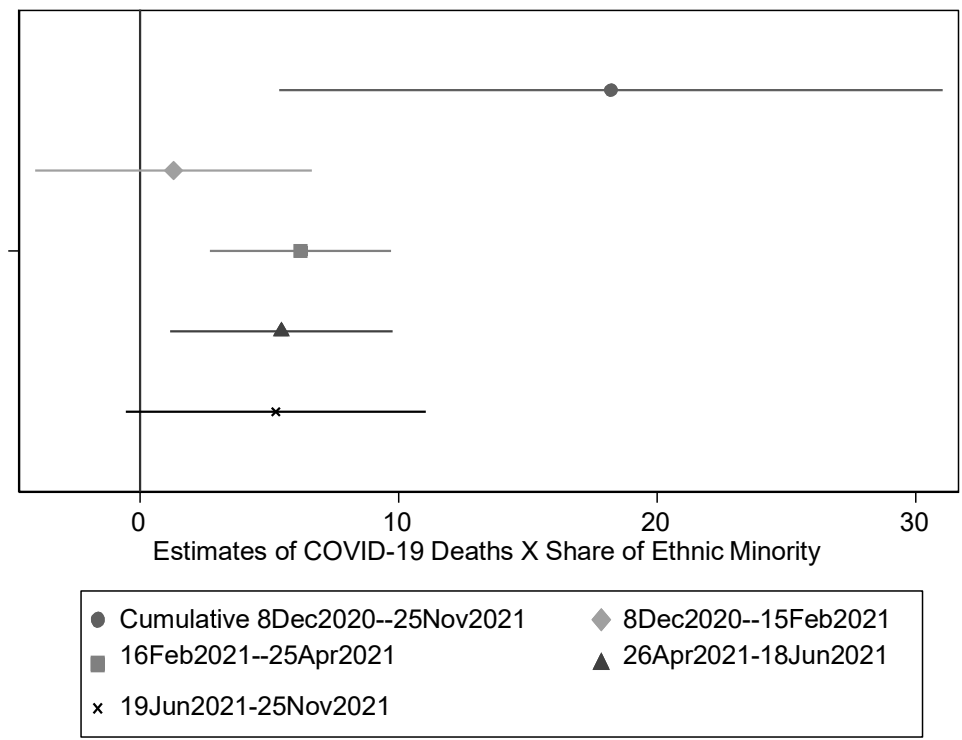

Figure 1: Timing of the effect

Notes: The graph represents the coefficient estimates and confidence intervals for the interaction variable COVID-19 Deaths $\times$ Share of Ethnic Minority from the regression model in Table 1 Column II, estimated both for the full period (Cumulative 8 Dec 2020 - 25 Nov 2021) and for different time intervals representing key phases of the COVID-19 vaccination program.

\subsection{ROBUSTNESS AND PLACEBO TESTS}

\subsubsection{ROBUSTNESS}

In our robustness analysis, we first assess whether our results are sensitive to the functional form and measures of deaths and vaccinations used in our baseline estimation of equation (2). These checks are presented in Table A5 in Appendix A and largely confirm our findings. In the first column, we estimate a log-log specification that also includes a control for total population. In Column II, we construct vaccination rates using the number of administered second doses. Both tests confirm our results. In the last two columns, we provide results using alternative measures of death rates: in Column III, we measure the "relative" COVID-19 death rate as the fraction of COVID- 19 deaths over deaths for all causes in each MSOA; in Column IV, we define the COVID-19 death rate as the difference between total deaths (for all causes) 
between March and November 2020 and the average number of deaths that took place in these months for 2015-2019. We then divide this by the population in the MSOA to obtain a measure of death rate. Both robustness checks confirm our main results.

The second type of robustness analysis we perform is to check whether our results are sensitive to how we measure the presence of ethnic groups. This analysis is presented in Table A6. We find that the results are robust to a different definition of the reference white ethnic group that includes only the white British. We also find that the response to death rate is stronger in localities that are more ethnically diverse (as measured by a Herfindahl index) and that have higher ethnic density (measured as the total non-white ethnic population divided by the MSOA area in hectares).

One might wonder if a similar pattern of results would be observed if we focused on the prevalence of COVID-19 cases instead of deaths. In Table A7, we report estimates of the same specifications reported in Table 1, replacing death rate by case rate. We find a similar pattern as above: cases are positively associated with vaccination rates, and areas with larger concentration of ethnic minorities have a stronger positive and statistically significant reaction.

\subsubsection{PLACEBO TESTS}

We perform two placebo tests as checks of our identification strategy. The first placebo test is reported in Figure A3. In this test, we perform randomization inference whereby we permute the value of the COVID-19 death rate with values from other MSOAs within the same LAD. We then simulated 5,000 regressions of the model in Table 1 Column I and obtained a set of estimates that we compared with our baseline estimates of COVID-19-death rate from Column I of Table 1. If our results were not driven by chance, we would have expected the simulations to generate estimates exceeding our baseline in only rare occasions. This is indeed what the results of this test show since no simulation produced a larger estimate than our baseline estimate.

In the second set of placebo tests reported in Table A4, we test the correlation between the COVID-19 death rate and the outcome from public health screening and immunization programs, which pre-date the beginning of the pandemic. Specifically, we consider the MSOA coverage of the NHS cervical screening program for the period 2019-2020, defined as the fraction of women aged 25 to 49 who underwent screening out of all eligible women of the 
same age. We also consider the vaccination rate related to three child immunization programs: seasonal flu, Meningococcal B (MenB), and Rotavirus. We define vaccination rates as the number of vaccinations in each MSOA over total population ${ }^{10}$. The rationale of these placebos is to provide a proxy for preventive health behaviour at the MSOA level that (i) pre-dates the pandemic and thus should not be affected directly or indirectly by COVID-19 death rates in the locality and, (ii) arguably does not influence COVID-19 death rates, which were driven mainly by individuals of old age, while these programs mainly concern groups, which are not among the most vulnerable to COVID-19. The results of these placebo tests indicate no statistically significant association between COVID-19 death rate and any of these outcomes, providing additional reassurance that the MSOA-level COVID-19 death rate can be considered conditionally exogenous for the scope of our analysis.

\section{INDIVIDUAL LEVEL EVIDENCE}

We next turn attention to results obtained using the individual-level data to estimate Equation (3). These are presented in Table 3. Recall that the dependent variable here is intention to vaccinate. In Column I, we find that, consistent with the locality-level analysis, ethnic minorities have lower intention to vaccinate, but their intention increases with the size of the local COVID-19 death rate faster than that of the majority group $(p<0.1)$. To gain a sense of the size of this effect, for an ethnic minority, an interquartile increase in the death rate $(0.084)$ increases the probability of declaring an intention to vaccinate by almost 4.9 percentage points. Considering that the ethnic gap in vaccination intention is 16.1 percentage points (Column 1 of Table 3), this implies a closing of the ethnic gap in vaccinations by almost one-third.

\subsection{HETEROGENEITY}

In the analysis so far, we have classified all ethnic minorities into the same group. In Column II, we look at the heterogeneity of the effect for ethnic minorities of different age groups relative to whites of all ages. What we find was that the younger age group (under 50) is the most responsive: an interquartile increase in the death rate increases their vaccination intention

\footnotetext{
${ }^{10}$ Note that screening and vaccination data are available at the Practice (GP) level. The counts at the MSOA level have been obtained by re-proportioning the GP-level counts using the share of patients from each practice that pertains to an MSOA, which was derived using the number of patients registered at a GP practice by LSOA of residence.
} 
probability by about 7.1 percentage points $(\mathrm{p}<0.01)$, whereas, for the older age group (over 50 ), the effect is negative but not statistically significant. The second split that we perform in Column III was to classify ethnic groups into two subgroups based on their average intention to vaccinate. We thus create two subgroups, one containing those ethnic groups that have the lowest intention (White and Black Caribbean, Pakistani, Bangladeshi, Caribbean, African, Any Other Black, Arab) and another containing the rest of the ethnic minority groups. We find that for individuals belonging to the low-intention group, there is evidence of a positive reaction to the death rate relative to whites $(p<0.01)$, with an interquartile increase in the death rate increasing the vaccination intention probability by about 8.6 percentage points. However, for the high-intention group, the effect is negative but again not statistically significant. This pattern suggests that the vaccination decision of groups or individuals that are more hesitant to start with is more likely to be influenced by deaths.

\subsection{ADDITIONAL RESULTS ON ETHNIC MINORITIES}

We next zoom in on ethnic minorities to perform some additional analysis and to probe why they have a stronger reaction to the local death rate.

One shortcoming of the data is that we do not observe deaths by ethnicity at the local level. However, at the individual level, we can approximate the social proximity to someone who might have died due to COVID. We do this by interacting the local death rate by the size of one's own ethnicity group in the locality. This analysis is reported in Table 4. We find that ethnic minorities living in areas with larger own-ethnic groups are more positively affected by the death rate. This is consistent with the idea that a larger network makes it more likely that if a member of their own ethnic group has died, they are informed about it.

So far, we have been presenting results for intentions to vaccinate prior to the rollout of the program. For a subset of individuals, we can look into actual vaccination as of March 2021, three months into the program. We repeat the analysis discussed above using actual vaccination in the last two columns of Table 4. Reassuringly, the results are consistent, although the sample is slightly smaller. 


\begin{tabular}{|c|c|c|c|c|}
\hline & 1 & 2 & 3 & 4 \\
\hline MSOA COVID-19 Death Rate $(\times 100)$ & $\begin{array}{r}.048 \\
(.125)\end{array}$ & $\begin{array}{l}-.038 \\
(.120)\end{array}$ & $\begin{array}{l}-.041 \\
(.119)\end{array}$ & $\begin{array}{l}-.059 \\
(.120)\end{array}$ \\
\hline Ethnic Minority & $\begin{array}{l}-.161^{* * * *} \\
(.035)\end{array}$ & $\begin{array}{l}-.166^{* * *} \\
(.035)\end{array}$ & & \\
\hline MSOA COVID-19 Death Rate $(\times 100) \times$ Ethnic Minority & & $\begin{array}{r}.623^{*} \\
(.361)\end{array}$ & & \\
\hline Ethnic Minority Age 16-49 & & & $\begin{array}{l}-.164^{* * *} \\
(.041)\end{array}$ & \\
\hline Ethnic Minority Age 50+ & & & $\begin{array}{l}-.170^{* * *} \\
(.051)\end{array}$ & \\
\hline MSOA COVID-19 Death Rate $(\times 100) \times$ Ethnic Minority Age 16-49 & & & $\begin{array}{l}.895^{* * *} \\
(.337)\end{array}$ & \\
\hline MSOA COVID-19 Death Rate $(\times 100) \times$ Ethnic Minority Age 50+ & & & $\begin{array}{l}-.267 \\
(.602)\end{array}$ & \\
\hline Ethnic Minority Low Vaccination Intentions & & & & $\begin{array}{l}-.287^{* * *} \\
(.046)\end{array}$ \\
\hline Ethnic Minority High Vaccination Intentions & & & & $\begin{array}{l}-.043 \\
(.040)\end{array}$ \\
\hline MSOA COVID-19 Death Rate $(\times 100) \times$ Ethnic Minority Low Vaccination Intentions & & & & $\begin{array}{l}1.077^{* * *} \\
(.389)\end{array}$ \\
\hline MSOA COVID-19 Death Rate $(\times 100) \times$ Ethnic Minority High Vaccination Intentions & & & & $\begin{array}{l}-.281 \\
(.500)\end{array}$ \\
\hline Local Authority District Fixed Effects & Yes & Yes & Yes & Yes \\
\hline $\mathrm{N}$ & 7,955 & 7,955 & 7,955 & 7,955 \\
\hline$R^{2}$ & .21 & .21 & .21 & .22 \\
\hline
\end{tabular}

Table 3: COVID-19 deaths and vaccination intentions - microdata evidence

Notes: Robust standard errors clustered at the MSOA level in parentheses. Regressions are weighted using crosssectional individual web survey weights.

The dependent variable is a binary variable for vaccination intention. This is based on the question "Imagine that a vaccine against COVID-19 was available for anyone who wanted it. How likely or unlikely would you be to take the vaccine?" with answers "Very Likely" and "Likely" coded as 1 and answers Unlikely and Very Unlikely coded as 0 .

MSOA COVID-19 Death Rate is defined as the cumulative number of COVID-19 deaths between 1st March 2020 and 30th November 2020 in the MSOA divided by total population in the MSOA. Values are multiplied times 100 for ease of interpretation.

High Vaccination Intentions include the following ethnic groups: White and Black Caribbean, Pakistani, Bangladeshi, Caribbean, African, Any Other Black, Arab.

Low Vaccination Intentions include the following ethnic groups: White and Black African, White and Asian, Any Other Mixed Background, Indian, Chinese, Any Other Asian Background, Any Other Ethnic Group.

The regression includes the following control variables at the individual level: dummies for gender, quinary age groups, being in a partnership, having kids in school age, having elderly in the household, having poor health, being foreign-born, having a degree, having no qualifications, being employed, receiving Universal Credit; income and a dummy for missing income.

The regression includes the following covariates at the MSOA level: \% Aged 16-29, \% Aged 30-49, \% Aged 5064 , \% Aged 65-79, \% Aged 80+, Share of Ethnic Minority, Index of Multiple Deprivation, Seasonal Flu Vaccination Rate and Non-COVID Death Rate.

$* \mathrm{p}<0.10$; $* * \mathrm{p}<0.05$; $* * * \mathrm{p}<0.01$. 


\begin{tabular}{lcccc}
\hline & \multicolumn{2}{c}{ Intentions } & \multicolumn{2}{c}{ Vaccinations } \\
\hline MSOA COVID-19 Death Rate $(\times 100)$ & $.975^{* *}$ & $2.152^{* * *}$ & $.839^{*}$ & $1.644^{* *}$ \\
Size of Ethnic Network & $(.447)$ & $(.538)$ & $(.482)$ & $(.716)$ \\
& & -.035 & & -.006 \\
MSOA COVID-19 Death Rate $\times$ Size of Ethnic Network & & $(.029)$ & $(.027)$ \\
& & $.573^{* * *}$ & $.434^{*}$ \\
$\mathrm{~N}$ & & $(.190)$ & & $(.241)$ \\
$R^{2}$ & 851 & 851 & 581 & 581 \\
\hline
\end{tabular}

Table 4: Additional results on ethnic minorities

Notes: Robust standard errors clustered at the MSOA level in parentheses. Regressions are weighted using crosssectional individual web survey weights.

The dependent variable in the first two columns is a binary variable for vaccination intention. This is based on the question "Imagine that a vaccine against COVID-19 was available for anyone who wanted it. How likely or unlikely would you be to take the vaccine?" with answers "Very Likely" and "Likely" coded as 1 and answers Unlikely and Very Unlikely coded as 0.

The dependent variable in last two columns is a binary variable for vaccination take-up in March 2021. This is based on the question 'Have you had a coronavirus vaccination?' with answers Yes, first vaccination only, Yes, both vaccinations and No, but I have an appointment coded as 1 and 0 otherwise.

Size of Ethnic Network is defined as the log number of individuals of the same ethnicity living in the MSOA. The ethnic groups considered are: White, White and Black Caribbean, White and Black African, White and Asian, Other Mixed, Pakistani, Indian, Bangladeshi, Chinese, Other Asian, African, Caribbean, Other Black, Arab, Any other ethnic groups.

The regression includes all the covariates of Table 3.

$* \mathrm{p}<0.10$; $* * \mathrm{p}<0.05$.; $* * * \mathrm{p}<0.01$.

\section{CONCEPTUAL FRAMEWORK}

Let us now understand our empirical results by developing a simple model that provides a possible mechanism of our results. The theoretical model is presented in Appendix B. We provide here the main idea. In this model, individuals decide whether or not to vaccinate, weighing in the costs and benefits arising from a desire to conform to what others in the community do. Given that individuals have different observable and unobservable characteristics, we determine a threshold value above which individuals get vaccinated. We then show that ethnic minorities get less vaccinated than the majority group because either their cost of getting vaccinated is higher or because their benefits are lower. Finally, we examine how exogenous deaths from COVID-19 in the local community affect the decision to get vaccinated. We show that local death rates affect more minority than majority vaccination rates if the difference in the marginal benefit of vaccination between the majority and minority group 
exceeds the difference in the marginal cost of vaccination. This condition is more likely to hold if, for example, information circulates better in the minority group because of their close-knit networks.

\section{CONCLUSION}

In recent years, many countries are witnessing a rising trend in vaccination refusal and hesitancy that is being associated with outbreaks of vaccine-preventable diseases; this has raised serious concerns among public health officials (Larson et al., 2014; Phadke et al., 2016; De Figueiredo et al., 2020; Sallam, 2021). The rapid development and rolling-out at scale of the vaccine for COVID-19 has been hailed as a major breakthrough in the global fight against the pandemic. Despite the initial optimism, vaccine take-up has been far from universalespecially among racial and ethnic minorities-even in countries with ample supply. Understanding what drives the decision of resisting vaccination is imperative for public policies. In this study, we contribute to the discussion by providing evidence that COVID- 19 mortality measured locally induces demand for vaccination in England, in particular, for ethnic minority groups. We conjecture that this finding is explained by the fact that ethnic communities are more tightly connected; thus, when a community member falls victim of the disease, the news spreads quickly and strongly affects other community members. In other words, social proximity to victims of the disease can trigger an urgency to take protective measures against it.

Our findings suggest that, to encourage vaccination among hesitant groups, vaccination campaigns should aim at facilitating the diffusion of information among members of highly hesitant groups about the actual local impact of the disease - that the vaccine is designed to eliminate - at the neighbourhood or community level. This could be achieved, for instance, by mobilizing influential members of these communities (e.g., community leaders) or families of patients and victims. 


\section{REFERENCES}

Ahituv, A., Hotz, V. J., \& Philipson, T. (1996) The responsiveness of the demand for condoms to the local prevalence of AIDS. Journal of Human Resources, 869-897.

Allington, D., McAndrew, S., Moxham-Hall, V., \& Duffy, B. (2021) Coronavirus conspiracy suspicions, general vaccine attitudes, trust and coronavirus information source as predictors of vaccine hesitancy among UK residents during the COVID-19 pandemic. Psychological Medicine, 1-12.

Auld, C. \& Toxvaerd, F. (2021) The great COVID-19 vaccine rollout: Behavioral and policy responses. CEPR Discussion Paper, No. DP16070.

Bandiera, O. \& Rasul, I. (2006) Social networks and technology adoption in Northern Mozambique. Economic Journal, 116, 869-902.

Battu, H., Seaman, P., \& Zenou, Y. (2011) Job contact networks and the ethnic minorities. Labour Economics, 18, 48-56.

Becker, G. S. (1968) Crime and punishment: An economic approach. Journal of Political Economy, 76(2), 169-217.

Bian, B., Li, J., Xu, T., \& Foutz, N. (2021) Individualism during crises. Review of Economics and Statistics, forthcoming.

Borjas, G. J. (1999) The economic analysis of immigration. Handbook of Labor Economics, 3, 16971760.

Carrieri, V., Madio, L., \& Principe, F. (2019). Vaccine hesitancy and (fake) news: Qyasi-experimental evidence from Italy. Health Economics, 28(11), 1377-1382.

Cawley, J. \& Ruhm, C. J. (2011) The economics of risky health behaviors. In Handbook of Health Economics, volume 2 (pp. 95-199). Elsevier.

Chang, L. V. (2018) Information, education, and health behaviors: Evidence from the MMR vaccine autism controversy. Health Economics, 27 (7), 1043-1062.

Conley, T. G. \& Udry, C. R. (2010) Learning about a new technology: Pineapple in ghana. American Economic Review, 100, 35-69.

Dahl, G. B., Løken, K. V., \& Mogstad, M. (2014) Peer effects in program participation. American Economic Review, 104(7), 2049-74.

Damm, A. \& Dustmann, C. (2014) Does growing up in a high crime neighborhood affect youth criminal behavior? American Economic Review, 104(6), 1806-1832.

De Figueiredo, A., Simas, C., Karafillakis, E., Paterson, P., \& Larson, H. J. (2020) Mapping global trends in vaccine confidence and investigating barriers to vaccine uptake: a large-scale retrospective temporal modelling study. The Lancet, 396(10255), 898-908.

Duflo, E. \& Saez, E. (2003) The role of information and social interactions in retirement plan decisions: Evidence from a randomized experiment. The Quarterly Journal of Economics, $118(3), 815-842$.

Epley, N. \& Gilovich, T. (2016) The mechanics of motivated reasoning. Journal of Economic Perspectives, 30(3), 133-40.

Eubank, N. (2019) Social networks and the political salience of ethnicity. Quarterly Journal of Political Science, 14, 1-39.

Funk, S., Gilad, E., Watkins, C., \& Jansen, V. A. (2009) The spread of awareness and its impact on epidemic outbreaks. Proceedings of the National Academy of Sciences, 106(16), 6872-6877.

Hansen, P. R. \& Schmidtblaicher, M. (2021) A dynamic model of vaccine compliance: How fake news undermined the Danish HPV vaccine program. Journal of Business \& Economic Statistics, 39(1), 259-271.

Hsieh, C.-S. \& van Kippersluis, H. (2018) Smoking initiation: Peers and personality. Quantitative Economics, 9, 825-863.

Islam, A., Ushchev, P., Zenou, Y., \& Zhang, X. (2018) The value of information in technology adoption: Theory and evidence from bangladesh. CEPR Discussion Paper, No. 13419. 
Larson, H. J., Jarrett, C., Eckersberger, E., Smith, D. M., \& Paterson, P. (2014) Understanding vaccine hesitancy around vaccines and vaccination from a global perspective: a systematic review of published literature, 2007-2012. Vaccine, 32(19), 2150-2159.

Loomba, S., de Figueiredo, A., Piatek, S. J., de Graaf, K., \& Larson, H. J. (2021) Measuring the impact of COVID-19 vaccine misinformation on vaccination intent in the UK and USA. Nature Human Behaviour, 5(3), 337-348.

Macintyre, K., Brown, L., \& Sosler, S. (2001) "it's not what you know, but who you knew": examining the relationship between behavior change and aids mortality in africa. AIDS Education and Prevention, 13(2), 160-174.

Marte'n, L., Hainmueller, J., \& Hangartner, D. (2019) Ethnic networks can foster the economic integration of refugees. Proceedings of the National Academy of Sciences of the USA, 116(33), $16280-16285$.

Martinez-Bravo, M. \& Stegmann, A. (2021) In vaccines we trust? The effects of the ClA's vaccine ruse on immunization in Pakistan. Journal of the European Economic Association, 544/2001.

Munshi, K. (2003). Networks in the modern economy: Mexican migrants in the us labor market. The Quarterly Journal of Economics, 118(2), 549-599.

Murphy, J., Vallie'res, F., Bentall, R. P., Shevlin, M., McBride, O., Hartman, T. K., McKay, R., Bennett, K., Mason, L., Gibson-Miller, J., et al. (2021) Psychological characteristics associated with COVID- 19 vaccine hesitancy and resistance in Ireland and the United Kingdom. Nature Communications, 12(1), 1-15.

Oster, E. (2018) Does disease cause vaccination? Disease outbreaks and vaccination response. Journal of Health Economics, 57, 90-101.

Patacchini, E. \& Zenou, Y. (2012) Ethnic networks and employment outcomes. Regional Science and Urban Economics, 42(6), 938-949.

Phadke, V. K., Bednarczyk, R. A., Salmon, D. A., \& Omer, S. B. (2016) Association between vaccine refusal and vaccine-preventable diseases in the united states: a review of measles and pertussis. Jama, 315(11), 1149-1158.

Philipson, T. (1996) Private vaccination and public health: An empirical examination for US measles. Journal of Human Resources, 611-630.

Platt, L. \& Warwick, R. (2020) Are some ethnic groups more vulnerable to covid-19 than others. Institute for fiscal studies, 1(05), 2020.

Qian, M., Chou, S.-Y., \& Lai, E. K. (2020) Confirmatory bias in health decisions: Evidence from the MMR-autism controversy. Journal of Health Economics, 70, 102284.

Razai, M. S., Osama, T., McKechnie, D. G., \& Majeed, A. (2021) Covid-19 vaccine hesitancy among ethnic minority groups, BMJ, 513. doi: 10.1136/bmj.n513.

Robertson, E., Reeve, K. S., Niedzwiedz, C. L., Moore, J., Blake, M., Green, M., Katikireddi, S. V., \& Benzeval, M. J. (2021) Predictors of covid-19 vaccine hesitancy in the uk household longitudinal study. Brain, Behavior, and Immunity, 94, 41-50.

Robinson, E., Jones, A., \& Daly, M. (2020) International estimates of intended uptake and refusal of covid-19 vaccines: A rapid systematic review and meta-analysis of large nationally representative samples. MedRxiv.

Sallam, M. (2021) Covid-19 vaccine hesitancy worldwide: a concise systematic review of vaccine acceptance rates. Vaccines, 9(2), 160.

University of Essex, ISER (2021) Understanding Society: COVID-19 Study, 2020-2021 [data collection]. 10th Edition. UK Data Service. 


\section{A Appendix: Additional Tables and Figures}

Figure A1: COVID-19 Death Rate and Ethnic Exposure - Locally weighted regression

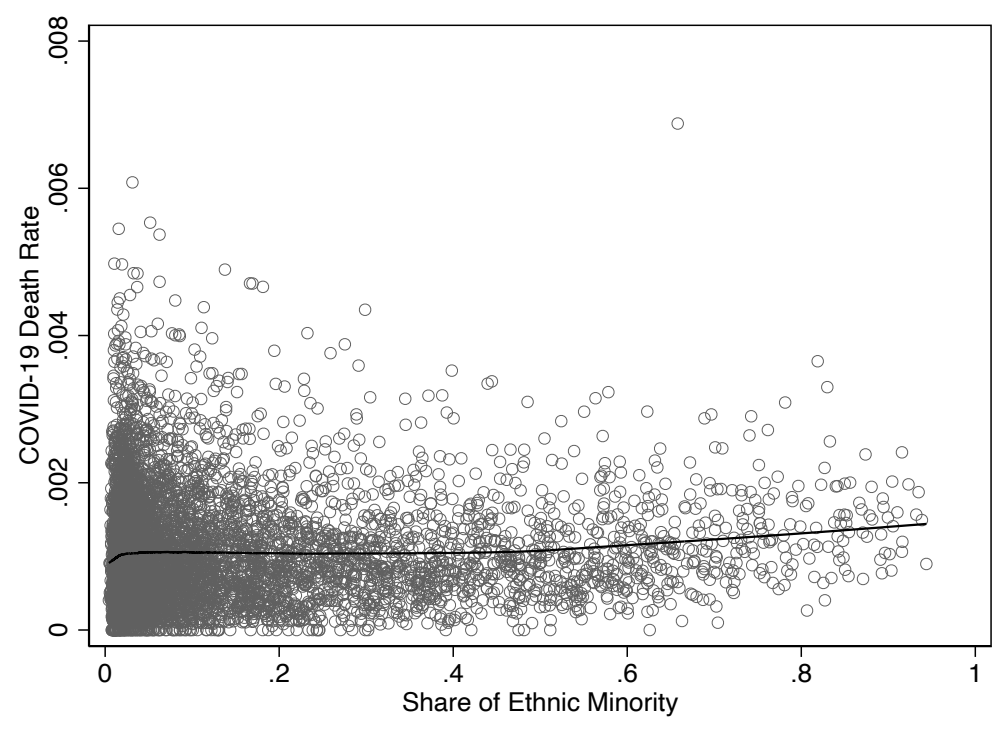

The graph represents locally weighted regressions of COVID-19 Death Rate on Ethnic Exposure. Each circle represents a MSOA. 
Figure A2: Density of Residualized Death Rate

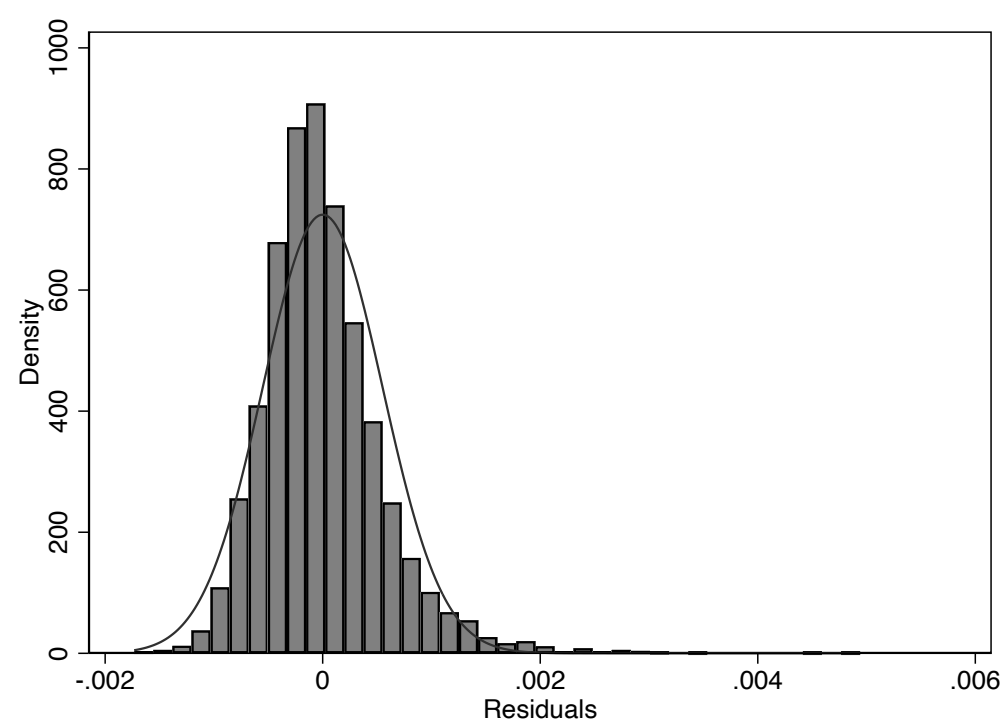

The graph represents the distribution of the residuals from a regression of COVID-19 Death Rate on all MSOA covariates included in Table 1 Col II, including LAD fixed effects.

Figure A3: Placebo: Randomization Inference

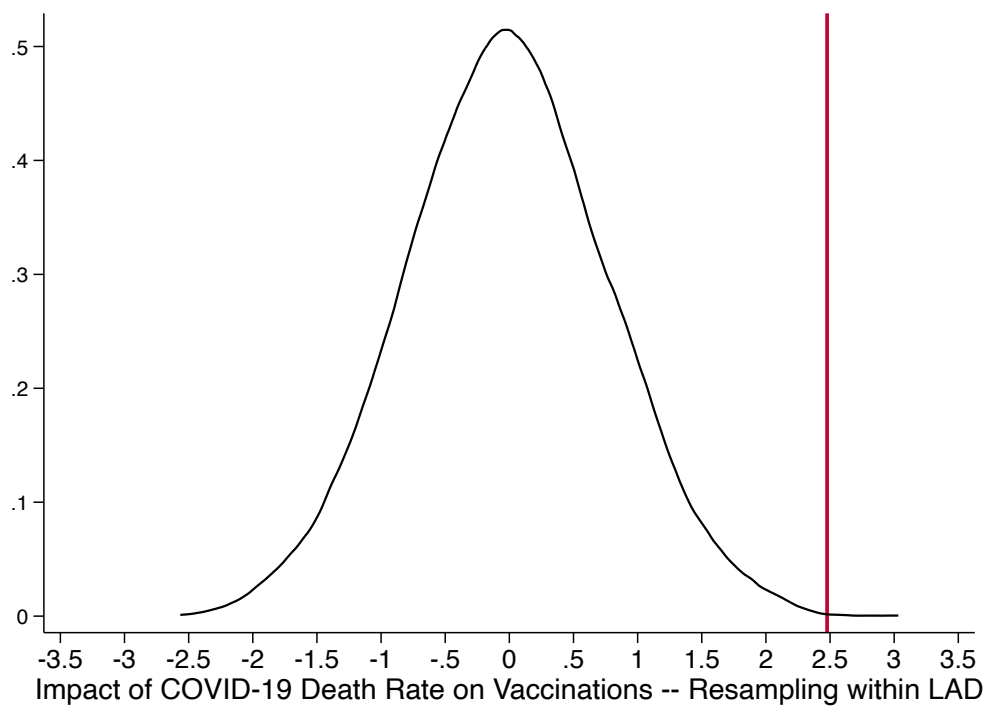

The graph represents the coefficient estimates for variable COVID-19 Deaths from simulations of the regression model in Table 1 column I where the variable COVID-19 Deaths has been permuted with values from other MSOA in the same LAD. $\mathrm{N}=5,000$ permutations. 
Figure A4: Maps of MSOAs
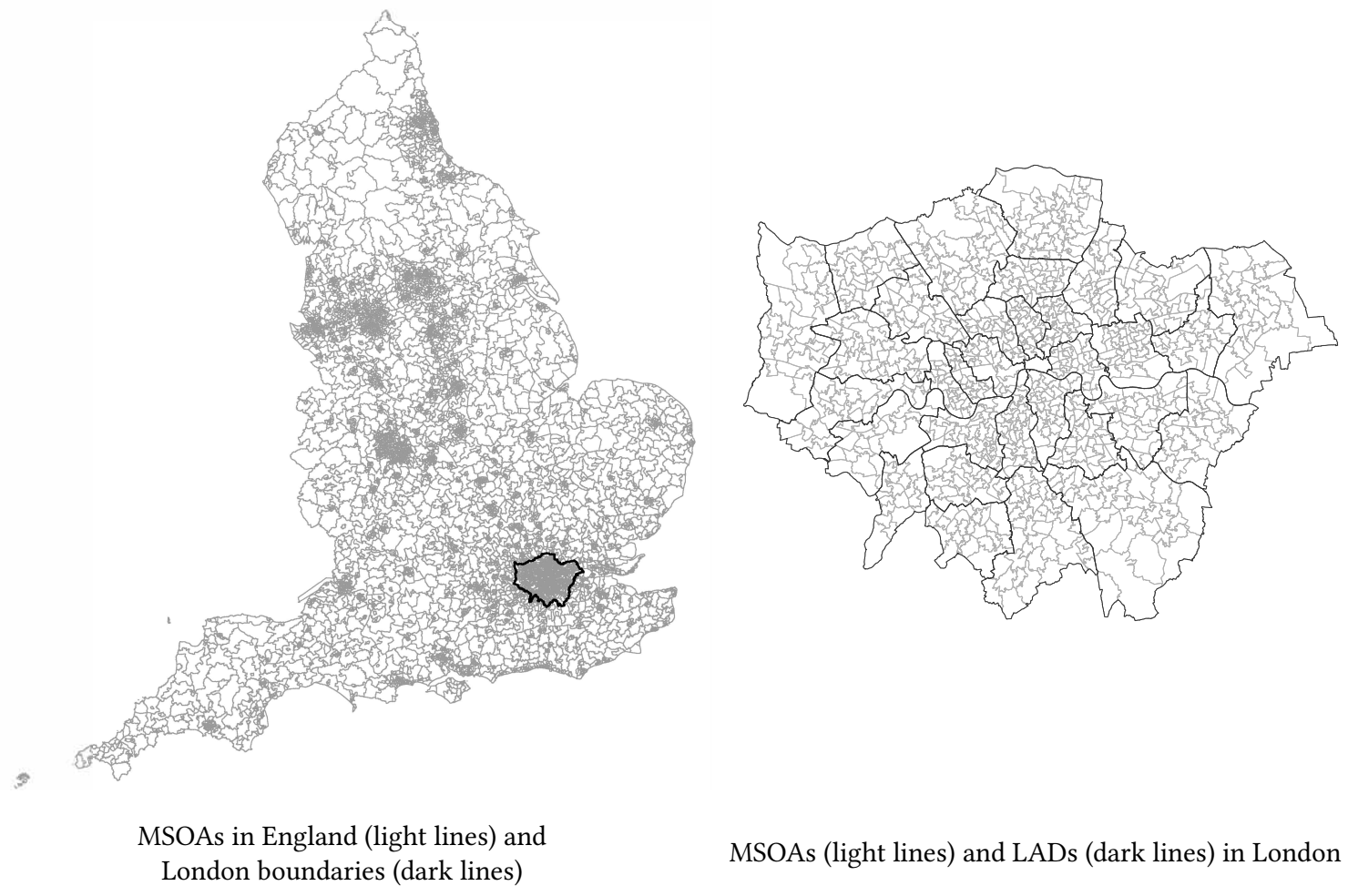

MSOAs (light lines) and LADs (dark lines) in London

Table A1: Key Characteristics of MSOAs and LADs

\begin{tabular}{|c|c|c|}
\hline & MSOA & LAD \\
\hline Number & 6,789 & 307 \\
\hline Avg. Population & 8,067 & 178,403 \\
\hline Avg. Area (in $10,000 \mathrm{~m}^{2}$ ) & 1,958 & 43,298 \\
\hline $\begin{array}{l}\text { Due to small numbers the } \\
\text { (City of London and Isles o } \\
\text { bined with other MSOAs). } \\
6,789 \text { instead of } 6,791 \text { MSOA }\end{array}$ & $\begin{array}{l}\text { ures for } \mathrm{t} \\
\text { illy have } \\
\text { is results } \\
\text { orming } \mathrm{E}\end{array}$ & $\begin{array}{l}\text { o MSOAs } \\
\text { in having } \\
\text { gland. }\end{array}$ \\
\hline
\end{tabular}




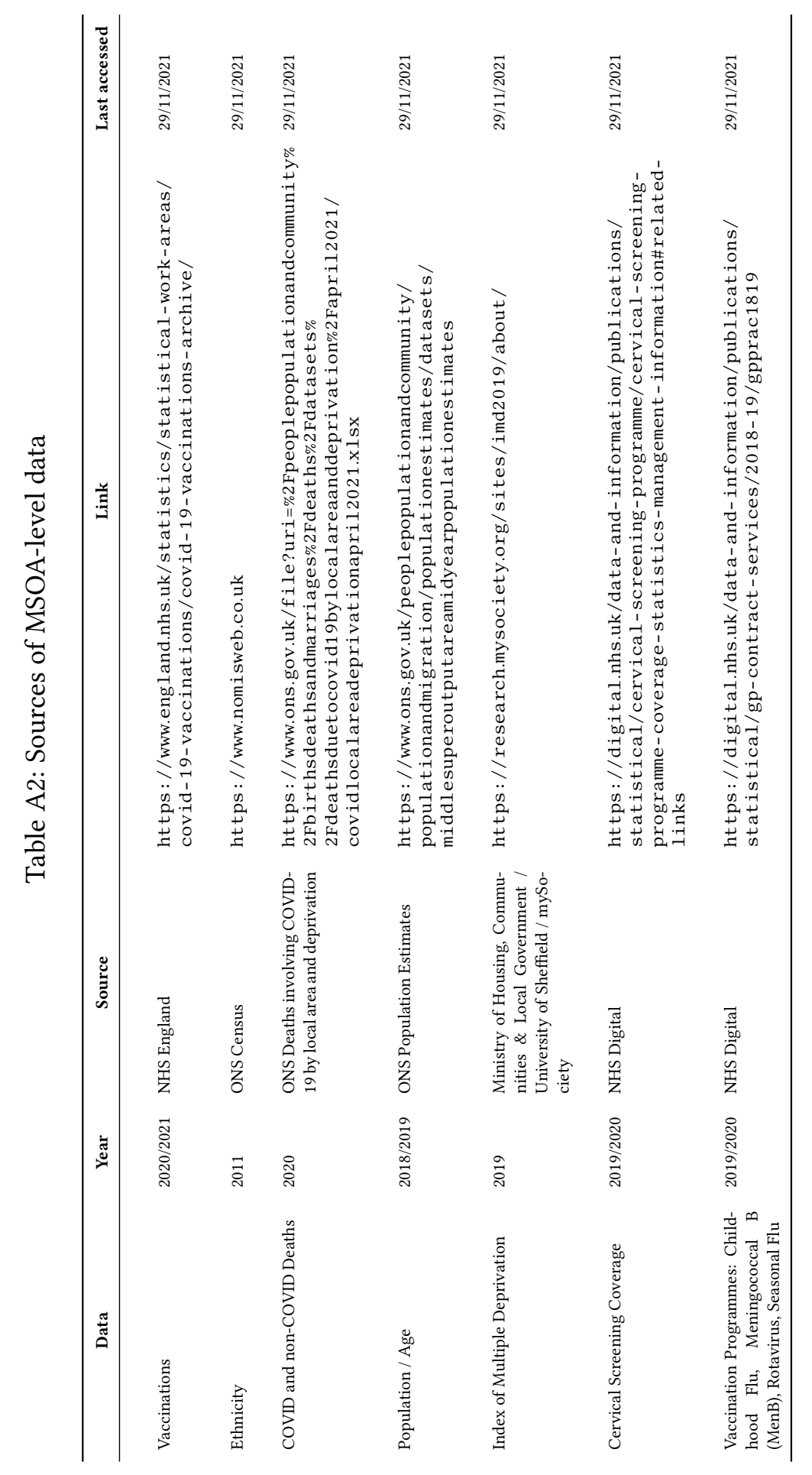


Table A3: Summary statistics - MSOA data

\begin{tabular}{lcc}
\hline \hline & Mean & SD \\
Vaccination Rate $-1^{\text {st }}$ dose & 0.752 & 0.088 \\
Vaccination Rate $-2^{\text {nd }}$ dose & 0.638 & 0.077 \\
COVID-19 Death Rate & 0.001 & 0.001 \\
Share of Ethnic Minority & 0.137 & 0.180 \\
\% Aged 16-29 & 0.167 & 0.072 \\
\% Aged 30-49 & 0.258 & 0.046 \\
\% Aged 50-64 & 0.194 & 0.036 \\
\% Aged 65-79 & 0.138 & 0.050 \\
\% Aged 80+ & 0.052 & 0.022 \\
Index of Multiple Deprivation & 0.216 & 0.132 \\
Seasonal Flu Vaccination Rate & 0.178 & 0.052 \\
Non-COVID Death Rate & 0.007 & 0.003 \\
2015-2019 Death Rate & 0.007 & 0.002 \\
\hline \hline
\end{tabular}

$\mathrm{N}=6,789$. Vaccination take-up rate is the cumulative number of first dose vaccinations between $8^{\text {th }}$ December 2020 and $25^{\text {th }}$ November 2021 divided by total population in the MSOA.

COVID-19 Death Rate is defined as the cumulative number of COVID-19 deaths between $1^{\text {st }}$ March 2020 and $30^{\text {th }}$ November 2020 in the MSOA divided by total population in the MSOA.

Ethnic Exposure is defined as the \% of ethnic minorities in the MSOA population.

The age variables represents the $\%$ of each group in the MSOA population.

Seasonal Flue Vaccination Rate refers to the vaccination rate of the seasonal flu for the period 2019/2020, defined as the total number of vaccinations over the population in the MSOA

The Index of Multiple Deprivation is based on 39 indicators and covers seven domains of deprivation: Income; Employment; Health Deprivation and Disability; Education, Skills Training; Crime; Barriers to Housing and Services; Living Environment. The score is divided by 100 for ease of interpretation.

Non-COVID Death Rate is defined as the cumulative number of deaths not attributed to COVID-19 between March 2020 and November 2020 in the MSOA divided by total population in the MSOA.

2015-2019 Death Rate refers to the average death rate between 2015 and 2019 referred to the interval MarchNovember of each year. 
Figure A5: Predictions of Vaccination Rates by Different Values of COVID-19 Deaths

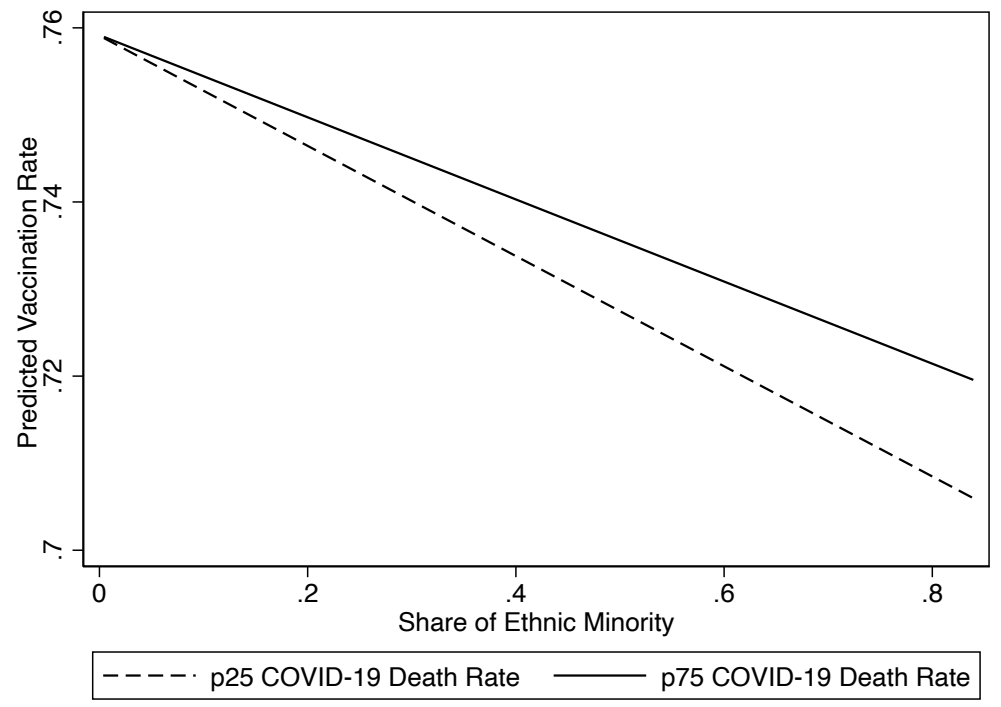

The graph represents predictions of the vaccination rate based on the estimates from the regression model in Table 1 column II for different values of the Share of Ethnic Minority (X-axis) and different values of COVID-19 Death Rate (dotted line: $25^{\text {th }}$ percentile; continuous line: $75^{\text {th }}$ percentile.) 
Table A4: Placebo Regressions

\begin{tabular}{lcccc}
\hline & Cervical & \multicolumn{3}{c}{ Children Vaccinations } \\
& Screening & Influenza & Men B & Rotavirus \\
\hline COVID-19 Death Rate & .486 & .021 & .060 & .037 \\
& $(.574)$ & $(.040)$ & $(.097)$ & $(.030)$ \\
& {$[.005]$} & {$[.006]$} & {$[.006]$} & {$[.013]$} \\
Seasonal Flu Vaccination Rate & $.378^{* * *}$ & $.022^{* * *}$ & $.012^{* *}$ & $.004^{* *}$ \\
& $(.016)$ & $(.001)$ & $(.005)$ & $(.002)$ \\
& {$[.272]$} & {$[.415]$} & {$[.093]$} & {$[.090]$} \\
\hline $\mathrm{N}$ & 6,789 & 6,789 & 6,789 & 6,789 \\
$R^{2}$ & .86 & .58 & .67 & .65 \\
\hline
\end{tabular}

Robust standard errors in parentheses. Standardized coefficients are presented in square brackets.

COVID-19 Death Rate is defined as the cumulative number of COVID-19 deaths between $1^{\text {st }}$ March 2020 and $30^{t h}$ November 2020 in the MSOA divided by total population in the MSOA.

Cervical Screening: The dependent variable is the coverage of the Cervical Screening Programme in the MSOA, defined as the fraction of women aged 2549 who underwent cervical screening out of eligible women aged 25-49 in the MSOA.

Children Vaccinations: The dependent variable is the vaccination rate of one of the three programmes (Childhood seasonal influenza vaccination programme, Meningococcal B (MenB) infants vaccination programme, Rotavirus vaccination programme) defined as the number of children who received the vaccine between 01 April 2019 to 31 March 2020 divided by the MSOA population.

The counts of screenings/vaccination comes at GP-level; counts at MSOA level have been obtained by reproportioning the GP-level counts using the \% of patients from each practice that pertains to an MSOA which was derived using the number of patients registered at a GP practice by LSOA of residence.

The regression contains all covariates of Table 1 Column I, including LAD fixed effects.

${ }^{*} p<0.10$; $\quad{ }^{* *} p<0.05$; $\quad{ }^{* * *} p<0.01$. 
Table A5: Robustness Checks

\begin{tabular}{lcccc}
\hline & 1 & 2 & 3 & 4 \\
\hline COVID-19 Death Rate & $.003^{* *}$ & $2.286^{* * *}$ & $.013^{* *}$ & .686 \\
& $(.001)$ & $(.794)$ & $(.005)$ & $(.419)$ \\
& {$[.011]$} & {$[.022]$} & {$[.020]$} & {$[.010]$} \\
Share of Ethnic Minority & $-.115^{* * *}$ & $-.077^{* * *}$ & $-.050^{* * *}$ & $-.050^{* * *}$ \\
& $(.013)$ & $(.007)$ & $(.008)$ & $(.008)$ \\
COVID-19 Deaths $\times$ Share of Ethnic Minority & {$[-.093]$} & {$[-.179]$} & {$[-.101]$} & {$[-.103]$} \\
& $(.010)$ & $(5.812)$ & $(.042)$ & $(3.366)$ \\
& {$[.021]$} & {$[.030]$} & {$[.016]$} & {$[.016]$} \\
\hline $\mathrm{N}$ & 6,789 & 6,789 & 6,789 & 6,789 \\
$R^{2}$ & .93 & .75 & .76 & .76 \\
\hline
\end{tabular}

Robust standard errors in parentheses. Standardized coefficients are presented in square brackets. The variables for the main effects of the interactions have been re-centered, hence the coefficients refer to their mean value.

Col I: Same as model in Column II of Table 1, but using log vaccinations in the MSOA instead of vacccination rate as depdendent variable, log COVID-19 deaths in the MSOA instead of death rate as main independent variable. The regression also includes a control for log population in the MSOA.

Col II: Same as model in Column II of Table 1, but the dependent variable refers to the second dose only.

Col III: Same as model in Column II of Table 1, but COVID-19 Death Rate is calculated as the total COVID-19 deaths over the total deaths (for all causes). This model does not include the Non-COVID Death Rate as control variable.

Col IV: Same as model in Column II of Table 1, but COVID-19 Death Rate is calculated as excess death, that is the difference between total deaths (for all causes) over the period $1^{\text {st }}$ March to $30^{\text {th }}$ November 2020 minus the average death rate for the years 2015-2019 referred to the same month interval (March-November). This model does not include the Non-COVID Death Rate as control variable.

${ }^{*} p<0.10$; $\quad{ }^{* *} p<0.05$; $\quad$ *** $p<0.01$. 
Table A6: Alternative Ethnicity Definitions

\begin{tabular}{lccc}
\hline & $\begin{array}{c}\text { Exposure } \\
\text { No W.B. }\end{array}$ & $\begin{array}{c}\text { Ethnic } \\
\text { Diversity }\end{array}$ & $\begin{array}{c}\text { Ethnic } \\
\text { Density }\end{array}$ \\
\hline COVID-19 Death Rate & $2.947^{* * *}$ & 1.455 & $2.264^{* * *}$ \\
& $(.884)$ & $(.896)$ & $(.872)$ \\
Alternative Ethnicity Definition & {$[.025]$} & {$[.012]$} & {$[.019]$} \\
& $-.080^{* * *}$ & .015 & $-.031^{* * *}$ \\
& $(.007)$ & $(.030)$ & $(.011)$ \\
COVID-19 Deaths $\times$ Alternative Ethnicity Definition & {$[-.194]$} & {$[.007]$} & {$[-.064]$} \\
& $15.115^{* * *}$ & $71.678^{* *}$ & $14.996^{* *}$ \\
& $(5.123)$ & $(35.440)$ & $(7.551)$ \\
$\mathrm{N}$ & {$[.025]$} & {$[.023]$} & {$[.019]$} \\
$R^{2}$ & 6,789 & 6,789 & 6,789 \\
\hline
\end{tabular}

Robust standard errors in parentheses. Standardized coefficients are presented in square brackets. The variables for the main effects of the interactions have been re-centered, hence the coefficients refer to their mean value.

Exposure No W.B: Same as model in Column II of Table 1, but Share of Ethnic Minority refers to all ethnic groups excluding White British.

Ethnic Diversity: Same as model in Column II of Table 1, but using the Herfindal Index instead of Share of Ethnic Minority. The Herfindal Index is defined as the sum of the square of the shares of each non-white ethnic group. The non-white ethnic groups are: White and Black Caribbean, White and Black African, White and Asian, Other Mixed, Indian, Pakistani, Bangladeshi, Chinese, Other Asian, African, Caribbean, Other Black, Arab, Any other ethnic groups

Ethnic Density: Same as model in Column II of Table 1, but using Ethnic Density instead of Share of Ethnic Minority. Ethnic Density is defined as the total non-white ethnic population divided by MSOA area in hectars.

${ }^{*} p<0.10 . ; \quad{ }^{* *} p<0.05 . ; \quad{ }^{* * *} p<0.01$. 
Table A7: COVID-19 cases and vaccination

\begin{tabular}{lccc}
\hline & 1 & 2 & 3 \\
\hline COVID-19 Cases Rate & $1.474^{* * *}$ & $1.374^{* * *}$ & $1.377^{* * *}$ \\
& $(.125)$ & $(.129)$ & $(.131)$ \\
Share of Ethnic Minority & {$[.249]$} & {$[.232]$} & {$[.232]$} \\
& $-.080^{* * *}$ & $-.094^{* * *}$ & $-.094^{* * *}$ \\
& $(.008)$ & $(.011)$ & $(.011)$ \\
COVID-19 Cases Rate $\times$ Share of Ethnic Minority & {$[-.164]$} & {$[-.192]$} & {$[-.192]$} \\
& & $.823^{* * *}$ & $.823^{* * *}$ \\
& & $(.313)$ & $(.312)$ \\
Local Authority District Fixed Effects & & {$[.035]$} & {$[.035]$} \\
$\mathrm{N}$ & Yes & Yes & Yes \\
$R^{2}$ & 6,786 & 6,786 & 6,786 \\
\hline
\end{tabular}

Robust standard errors in parentheses. Standardized coefficients are presented in square brackets. The variables for the main effects of the interactions have been re-centered, hence the coefficients refer to their mean value.

The dependent variable is vaccination rate in the Middle Super Output Area (MSOA), defined as the cumulative number of first dose vaccinations between $8^{\text {th }}$ December 2020 to $25^{\text {th }}$ November 2021 divided by total population in the MSOA. COVID-19 Cases is the cumulative number of cases between $7^{\text {th }}$ March 2020 to $30^{\text {th }}$ November 2020 in the MSOA divided by total population in the MSOA.

The regression includes all other controls of the corresponding columns of Table 1.

* $p<0.10$; $\quad{ }^{* *} p<0.05 . ; \quad * * * \quad p<0.01$. 
Table A8: Summary statistics - Microdata

\begin{tabular}{llc}
\hline \hline & Mean & SD \\
COVID-19 Vaccine Intention & 0.820 & 0.384 \\
Female & 0.533 & 0.499 \\
Age & 50.783 & 17.832 \\
Has Partner & 0.638 & 0.481 \\
N. Children in School & 0.365 & 0.788 \\
Has Elderly in Household & 0.145 & 0.353 \\
Poor Health & 0.039 & 0.192 \\
Foreign Born & 0.081 & 0.272 \\
Has Degree & 0.291 & 0.454 \\
Has No Qualifications & 0.053 & 0.225 \\
Employed & 0.601 & 0.490 \\
Weekly Income in $£$ & 614.365 & 487.639 \\
Receives Universal Credit & 0.064 & 0.245 \\
COVID-19 Death Rate $(\times 100)$ & 0.102 & 0.071 \\
Ethnic Exposure & 0.119 & 0.167 \\
MSOA \% Aged 16-29 & 0.161 & 0.064 \\
MSOA \% Aged 30-49 & 0.256 & 0.045 \\
MSOA \% Aged 50-64 & 0.197 & 0.035 \\
MSOA \% Aged 65-79 & 0.142 & 0.049 \\
MSOA \% Aged 80+ & 0.054 & 0.022 \\
MSOA Seasonal Flu Vaccination Rate & 0.187 & 0.051 \\
MSOA Index of Multiple Deprivation & 0.201 & 0.123 \\
MSOA Non-COVID Death Rate $(\times 100)$ & 0.680 & 0.250 \\
\hline \hline
\end{tabular}

$\mathrm{N}=7,972$. Statistics are weighted using cross-sectional individual web survey weights.

Income is expressed in $\mathfrak{f} / 1000$.

COVID-19 Death Rate is defined as the cumulative number of COVID-19 deaths between $1^{\text {st }}$ March 2020 and $30^{\text {th }}$ November 2020 in the MSOA divided by total population in the MSOA.

Share of Ethnic Minority is defined as the \% of ethnic minorities in the MSOA population.

The age variables represents the \% of each group in the MSOA population. Seasonal Flue Vaccination Rate refers to the vaccination rate of the seasonal flu for the period 2019/2020, defined as the total number of vaccinations over the population in the MSOA

The Index of Multiple Deprivation is based on 39 indicators and covers seven domains of deprivation: Income; Employment; Health Deprivation and Disability; Education, Skills Training; Crime; Barriers to Housing and Services; Living Environment. The score is divided by 100 for ease of interpretation.

Non-COVID Death Rate is defined as the cumulative number of deaths not attributed to COVID-19 between $1^{\text {st }}$ March 2020 and $30^{\text {th }}$ November 2020 in the MSOA divided by total population in the MSOA. 
Table A9: Social Network Characteristics by Ethnicity

\begin{tabular}{|c|c|c|c|c|}
\hline & \multicolumn{2}{|c|}{ White } & \multicolumn{2}{|c|}{ Ethnic Minority } \\
\hline & Mean & SD & Mean & $\mathrm{SD}$ \\
\hline Number of Named Friends & 2.719 & 0.579 & 2.528 & 0.711 \\
\hline Share of Ethnic Minority Friends & 0.031 & 0.122 & 0.783 & 0.344 \\
\hline Number of Activities done with Friends & 0.431 & 2.952 & 8.359 & 9.791 \\
\hline Number of Issues Discussed with Friends & 0.438 & 2.997 & 8.465 & 9.905 \\
\hline
\end{tabular}

Source: Understanding Society Wave 3 and 6.

N: 63,836 (White); 9595 (Ethnic Minority)

Ethnicity is defined as non-white ethnic groups

Number of Activities done with Friends refer to the number of activities done with each named friends, averaged over the number of named friends. The activities include: travel or take holidays together, watch sport, watch other tv, go to films, concerts or other events, just talk, web chat, go to pubs, cafes or clubs, go shopping, do sport or other types of exercise together, do other hobbies or activities together, eat together.

Number of Issues Discussed with Friends refer to the number of issues discussed with each named friends, averaged over the number of named friends. The topics include: tv, relationships, food \& drink, travel, music, sport, work, politics, religion, family or children, books, magazines, other hobbies or interests, films 


\section{B Appendix: Details of the Model}

\section{B.1 The model}

Consider two types of agents: majority $(M)$ and ethnic minorities $(m)$. Each individual $i=m, M$ can take one of the two actions: $V$ (Vaccination) and $N$ (No vacination). The utility $U_{i V}$ of agent $i$ who chooses $V$ is given by:

$$
U_{i V}=u\left(v_{i}\right)-\beta_{i} c_{i V}
$$

where $c_{i V}$ is the cost of vaccination for agent $i$ and $v_{i}$ is the fraction of individuals in $i$ 's community who choose to get vaccinated. For each individual $i$, there is a uniform distribution of the marginal cost of vaccination $\beta_{i}$ in population $i$ on the support $[0,1]$.

We assume that $u\left(v_{i}\right)$ is increasing in $v_{i}$, that is, the higher is the fraction of people from the same community who gets vaccinated, the higher is the utility for $i$ to get vaccinated.

Similarly, $U_{i N}$ is the utility that agent $i$ chooses not to get vaccinated. We have:

$$
U_{i N}=u\left(n_{i}\right)-c_{i N}
$$

where $c_{i N}$ is the cost of non-vaccination for agent $i$ (for example, getting sick or having side effects from the vaccination) and $n_{i}:=1-v_{i}$ is the fraction of individuals in $i$ 's community who choose not to get vaccinated. We assume that $u\left(n_{i}\right)$ is increasing in $n_{i}$ or decreasing in $v_{i}$. Denote by $\Delta u\left(v_{i}\right):=u\left(v_{i}\right)-u\left(n_{i}\right)$. This implies that

$$
\frac{\partial \Delta u\left(v_{i}\right)}{\partial v_{i}}=\frac{\partial u\left(v_{i}\right)}{\partial v_{i}}-\frac{\partial u\left(n_{i}\right)}{\partial v_{i}}>0
$$

This means that when the fraction of individuals who get vaccinated in a community increases, the difference in utility between vaccination and non-vaccination increases.

An agent $i$ will then choose $V$ (gets vaccinated) if and only if $U_{i V} \geq U_{i N}$, that is,

$$
\Delta u\left(v_{i}\right) \geq \beta_{i} c_{i V}-c_{i N}
$$

This is equivalent to

$$
\beta_{i} \leq d\left(v_{i}\right):=\frac{\Delta u\left(v_{i}\right)+c_{i N}}{c_{i V}} .
$$

where $d\left(v_{i}\right)$ is the threshold below which agents get vaccinated. Observe that $d\left(v_{i}\right)$ is increasing in $v_{i}$, so that the more people from $i$ 's community get vaccinated, the more likely individual $i$ will get vaccinated. Assume that

$$
\Delta u(0)>-c_{i N} \quad \text { and } \quad 0<\Delta u(1)<c_{i V}-c_{i N} .
$$


This guarantees that there is a unique solution to (B.5), so that there is a unique threshold $d\left(v_{i}\right)$. See Figure A6.

Figure A6: Equilibrium threshold

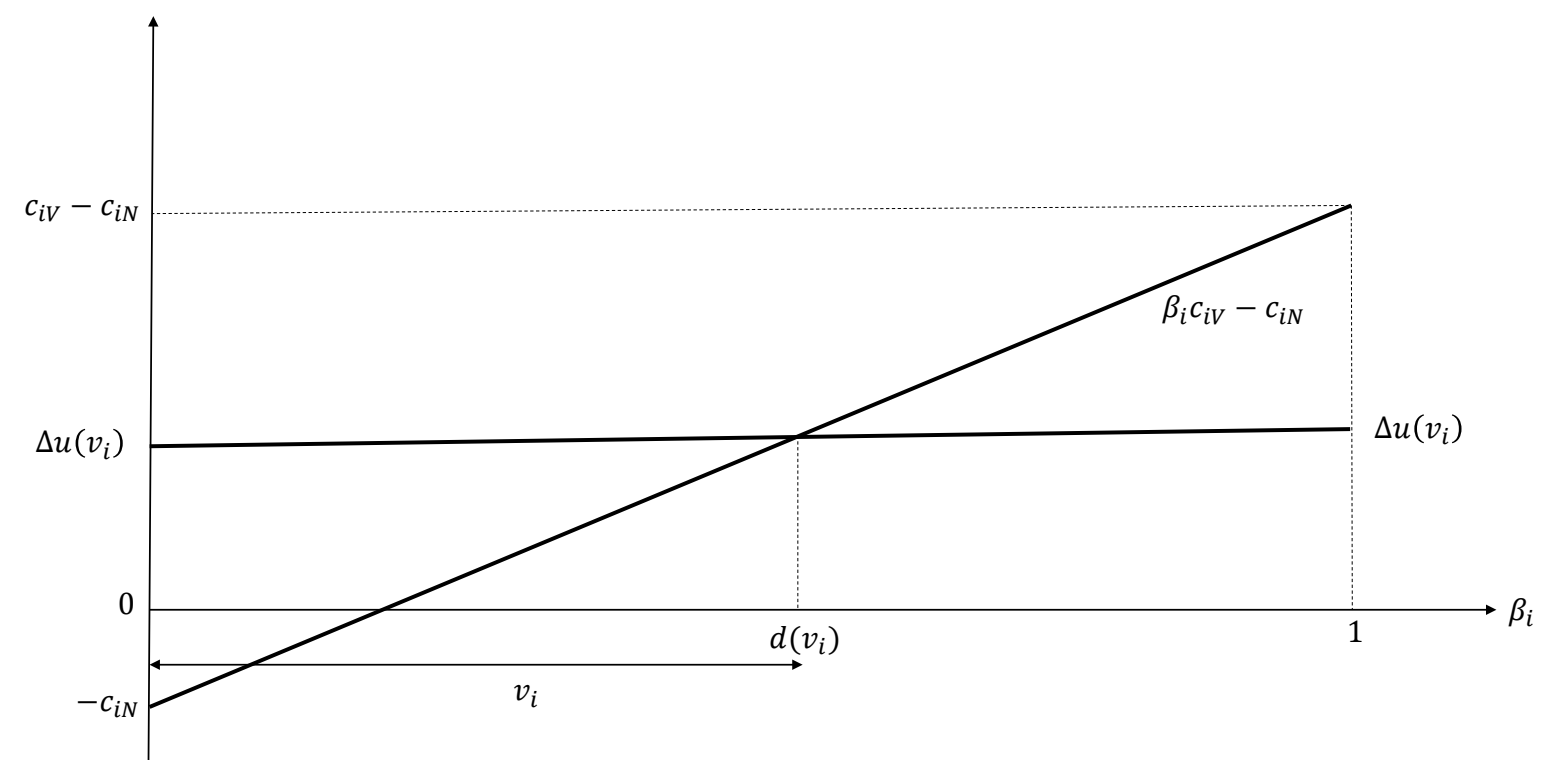

Since we have a uniform distribution of $\beta_{i}$ within community $i$ on the support $[0,1]$, we want to determine the probability of getting vaccinated in population $i$, that is $P\left(0<\beta_{i}<d\left(v_{i}\right)\right)$. We have:

$$
P\left(0<\beta_{i}<d\left(v_{i}\right)\right)=d\left(v_{i}\right)=\frac{\Delta u\left(v_{i}\right)+c_{i N}}{c_{i V}}
$$

We can now determine the $v_{i}^{*}$, the fraction of vaccinated in community $i$. It is given by:

$$
v_{i}=d\left(v_{i}\right)=\frac{\Delta u\left(v_{i}\right)+c_{i N}}{c_{i V}}
$$

By rearranging this equation, we obtain

$$
c_{i V} v_{i}^{*}-c_{i N}=\Delta u\left(v_{i}^{*}\right)
$$

Condition (B.6) guarantees that we have a unique solution to this equation. We have the following straightforward result: 
Proposition 1. Suppose that the conditions in (B.6) hold. Then, we have a unique equilibrium vaccination rate $0<v_{i}^{*}<1$ in community $i$ implicitly determined by (B.8). This vaccination rate increases with the cost of non-vaccination $c_{i N}$, but decreases with the cost of vaccination $c_{i V}$.

Figure A7 depicts the determination of the vaccination rate $v_{i}^{*}$.

Figure A7: Equilibrium vaccination rate

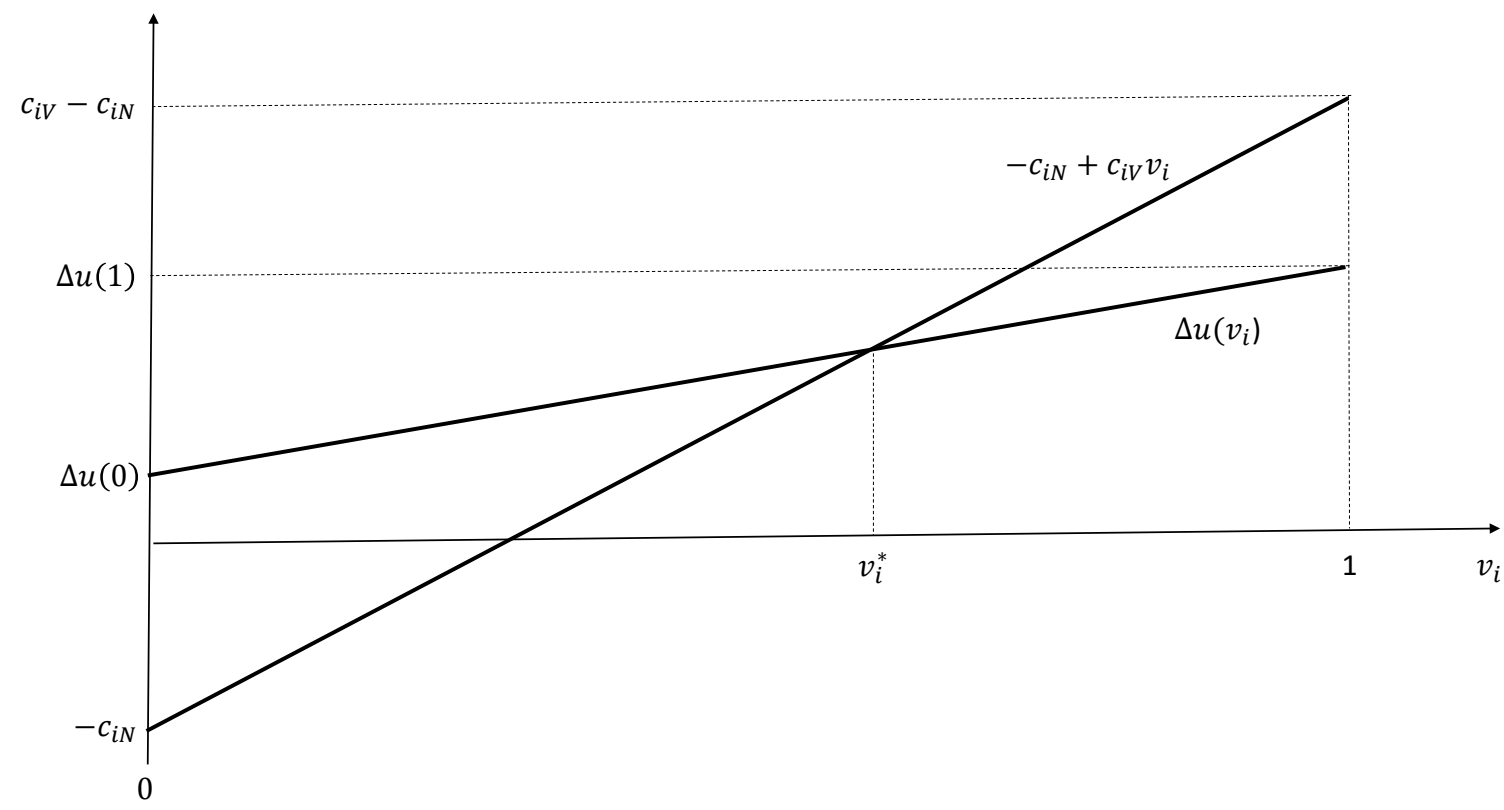

\section{B.2 Specific form of the utility function}

Assume that: $u\left(v_{i}\right)=\alpha_{i} v_{i}$ and that $u\left(n_{i}\right)=n_{i}=1-v_{i}$. In this formulation, $\alpha_{i}>1$ is the marginal utility of getting vaccinated when a fraction $v_{i}$ of the community gets vaccinated. ${ }^{11}$ This implies that

$$
\Delta u\left(v_{i}\right):=u\left(v_{i}\right)-u\left(n_{i}\right)=\left(1+\alpha_{i}\right) v_{i}-1
$$

As above assume that condition (B.6) holds, which here is equal to

$$
c_{i N}>1 \quad \text { and } \quad \alpha_{i}<c_{i V}-c_{i N}
$$

\footnotetext{
${ }^{11}$ We assume that $\alpha_{i}>1$ because we want the marginal utility of getting vaccinated to be higher than the marginal utility of not getting vaccinated. So, $\alpha_{i}$ is the marginal utility of getting vaccinated relative to not being vaccinated.
} 
This implies that the threshold defined in (??) is now given by

$$
d\left(v_{i}\right):=\frac{\left(1+\alpha_{i}\right) v_{i}+c_{i N}-1}{c_{i V}}
$$

The equilibrium vaccination rate is now given by:

$$
v_{i}=\frac{\left(1+\alpha_{i}\right) v_{i}+c_{i N}-1}{c_{i V}} .
$$

Solving this equation leads to

$$
v_{i}^{*}=\frac{c_{i N}-1}{c_{i V}-1-\alpha_{i}} .
$$

Condition (B.9) guarantees that $0<v_{i}^{*}<1$. Clearly, when the (marginal) benefits of vaccination $\alpha_{i}$ increases, the threshold $d\left(v_{i}\right)$ increases, which means that more individuals get vaccinated. This leads to a higher vaccination rate $v_{i}^{*}$ among agents in the same community as $i$. Similarly, when the cost of vaccination, $c_{i V}$, decreases or the cost of non-vaccination, $c_{i N}$, increases, the vaccination rate $v_{i}^{*}$ increases.

\section{B.3 Why ethnic minorities get less vaccinated than the majority group?}

In the empirical section, we showed that ethnic minorities get less vaccinated than the majority group. From our model, an obvious explanation of why ethnic minorities get less vaccinated is that the cost of getting vaccinated is higher for ethnic minorities than for the majority group, that is, $c_{m V}>c_{M V}$. Another possible explanation is that the benefits of getting vaccinated are lower. In our specific model of Section B.2, this is captured by $\alpha_{m}<\alpha_{M}$.

Clearly, if $c_{m V}>c_{M V}$ and/or $\alpha_{m}<\alpha_{M}$, then $d\left(v_{m}\right)<d\left(v_{M}\right)$ and ethnic minorities will need to have a higher fraction $v_{i}$ of their neighbors from their community who get vaccinated for them to get vaccinated. This leads to a lower vaccination rates, that is, $v_{m}^{*}<v_{M}^{*}$ (see Proposition 1). Since all ethnic minorities have a higher cost or a lower benefit of vaccination, this is less likely to occur and may explain the lower vaccination take-up rates and vaccination hesitancy among minorities. Figure A8 illustrates the different thresholds for ethnic minorities and the majority group when

$c_{m V}>c_{M V}, c_{m N}=c_{M N}, \alpha_{m}=\alpha_{M}$, and the distribution of $\beta_{i}$ is the same. We see that, because ethnic minorities experience a higher cost of vaccination, they have a lower threshold and thus vaccinate less than the majority group.

This assumption $c_{m V}>c_{M V}$ (and/or $\alpha_{m}<\alpha_{M}$ ) can be explained by the fact that ethnic minorities are more skeptical by a government action (such as vaccination) because they have had a bad experienced in the past with public action. For example, it is also possible that there is a narrative among ethnic minorities that the COVID 19 virus is a "hoax" and that the government uses vaccination to control people (use popular stories from newspapers to back up this narrative). This is 
Figure A8: Different thresholds for minority and majority groups when $c_{m V}>c_{M V}$

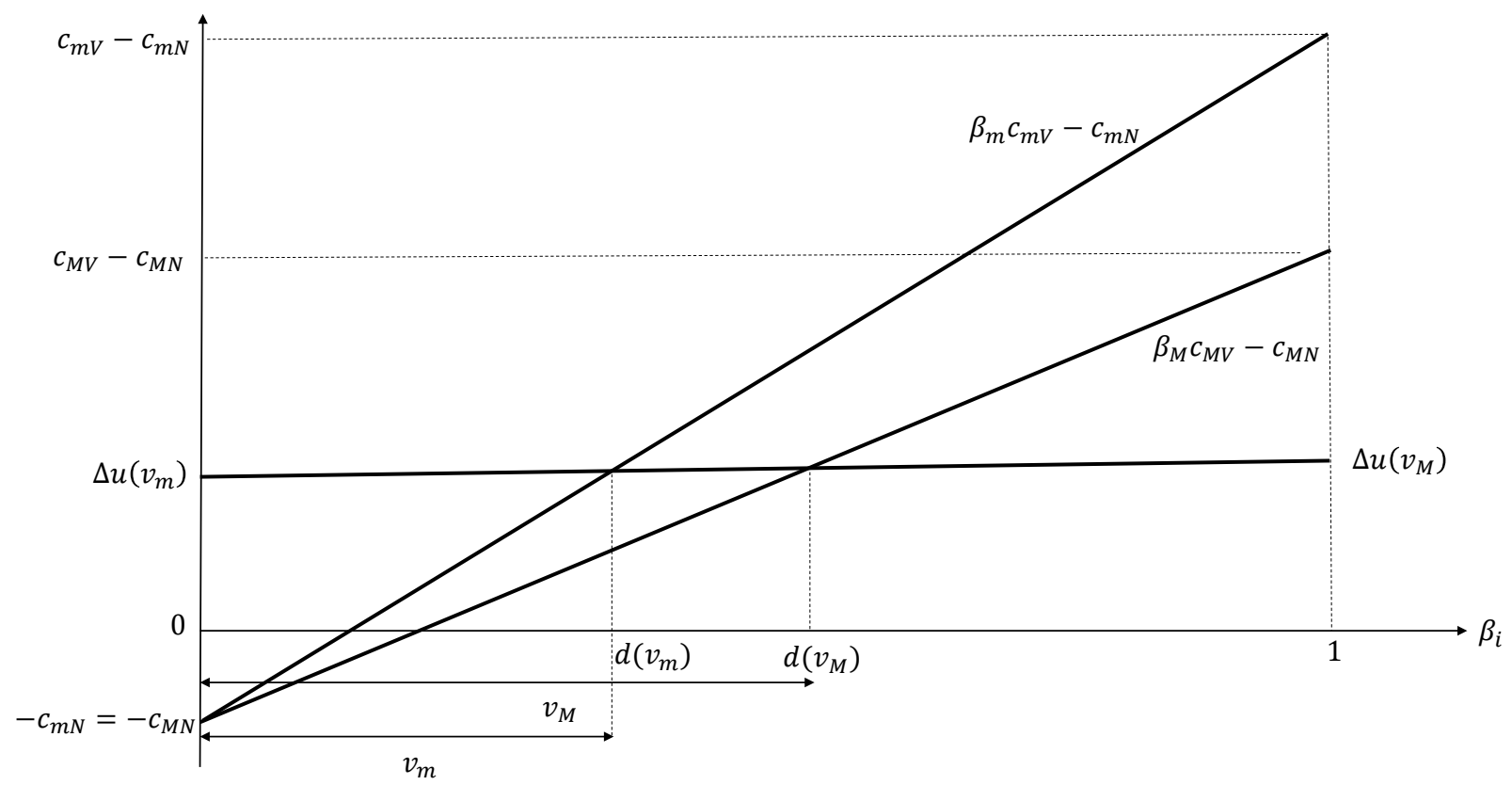

consistent with what we obtained in column I in Table 3 for the individual-level evidence (Section 5).

To understand our empirical results obtained at the locality level (Section 4), consider a given locality $l$ of size $L$, where $m_{l} \%$ of its residents are from the minority group and $\left(1-m_{l}\right) \%$ from the majority group. The vaccination rate $v_{i}^{*}$ of each group (or the probability that a randomly chosen individual in group $i$ gets vaccinated) is given by (B.8) or by (B.12). This means that there are $v_{m}^{*} m_{l} L$ individuals vaccinated among the minority group and $v_{M}^{*}\left(1-m_{l}\right) L$ vaccinated among the majority group. The vaccination rate in locality $l$ that we measure in the data is equal to: $v_{m}^{*} m_{l}+v_{M}^{*}\left(1-m_{l}\right)$, which we denote by $Y_{l}$ in equation (1) or (2). Consider the model of Section B.2. We have:

$$
v_{l}^{*}:=v_{m}^{*} m_{l}+v_{M}^{*}\left(1-m_{l}\right)=\frac{\left(c_{m N}-1\right) m_{l}}{c_{m V}-1-\alpha_{m}}+\frac{\left(c_{M N}-1\right)\left(1-m_{l}\right)}{c_{M V}-1-\alpha_{M}} .
$$

For simplicity, assume that $\alpha_{m}=\alpha_{M}=\alpha_{l}$, so that the only difference between the two groups is only in terms of cost, that is, as above, $c_{m V}>c_{M V}$ and $c_{m N}=c_{M N}=c_{N \cdot}{ }^{12}$ Assume also that condition (B.9) holds. We have:

$$
v_{l}^{*}:=\left[\frac{c_{N}-1}{c_{m V}-1-\alpha_{l}}-\frac{c_{N}-1}{c_{M V}-1-\alpha_{l}}\right] m_{l}+\frac{c_{N}-1}{c_{M V}-1-\alpha_{l}} .
$$

\footnotetext{
${ }^{12} \mathrm{We}$ also assume that the distribution of $\beta_{i}$ is the same for minority and majority individuals.
} 
By differentiating this equation, we obtain:

$$
\frac{\partial v_{l}^{*}}{\partial m_{l}}=\left[\frac{c_{N}-1}{c_{m V}-1-\alpha_{l}}-\frac{c_{N}-1}{c_{M V}-1-\alpha_{l}}\right]<0,
$$

since $c_{m V}>c_{M V}$. This is exactly what we obtained in the second row of columns I, II, or III in Table $1 .{ }^{13}$

\section{B.4 How observed deaths can change vaccination rates?}

When an ethnic minority observes a death from COVID 19 from someone from her local community, the narrative about the COVID 19 virus being a hoax is more difficult to sustain.

In our model, let us slightly change the utility function to capture this. Assume now that, instead of (B.2), the utility $U_{i N}$ of an agent $i$ who chooses action $N$ (i.e., not getting vaccinated) is given by:

$$
U_{i N}=u\left(1-v_{i}\right)-c_{i N} x_{i}
$$

where $x_{i}>1$ is the number of death in $i$ 's community. In other words, the higher is $x_{i}$, the higher is the cost of not getting vaccinated. As in the empirical analysis, $x_{i}$ is assumed to be an exogenous shock to $i$ 's community. For each individual $i$, there is a uniform distribution of the marginal benefit of vaccination $\beta_{i}$ in population $i$ on the support $[0,1]$. The utility of getting vaccinated is exactly the same as before and given by

An individual $i$ will get vaccinated if and only if

$$
\beta_{i} \leq d\left(v_{i}, x_{i}\right):=\frac{\Delta u\left(v_{i}\right)+c_{i N} x_{i}}{c_{i V}}
$$

Observe that $d\left(v_{i}, x_{i}\right)$ is increasing in $x_{i}$. Indeed, when $x_{i}$, the number of deaths in $i$ 's community, increases, the cost of not getting vaccinated increases. This leads to a higher value of the threshold $d\left(v_{i}, x_{i}\right)$, so that each agent $i$ needs a lower fraction of their neighbors' vaccination for them to get vaccinated. In turn, this implies a higher vaccination rate $v_{i}^{*}$. Indeed, the equilibrium vaccination rate is given by (B.8). In order to have a unique vaccination rate $0<v_{i}^{*}<1$, we need to assume that, $\forall x_{i}$, we have:

$$
\Delta u(0)>-c_{i N} x_{i} \quad \text { and } \quad \Delta u(1)<c_{i V}-c_{i N} x_{i} .
$$

If we differentiate (B.8), we obtain

$$
\frac{\partial v_{i}^{*}}{\partial x_{i}}=\frac{c_{i N}}{c_{i V}-\frac{\partial \Delta u\left(v_{i}\right)}{\partial v_{i}}}>0 .
$$

\footnotetext{
${ }^{13}$ We can clearly obtain the same result for the general model without specific functional form.
} 
where (see (B.3))

$$
\frac{\partial \Delta u\left(v_{i}\right)}{\partial v_{i}}=\frac{\partial u\left(v_{i}\right)}{\partial v_{i}}-\frac{\partial u\left(n_{i}\right)}{\partial v_{i}}>0 .
$$

As in the previous section, consider a locality $l$ of size $L$, where $m_{l} \%$ of its residents are from the minority group and $\left(1-m_{l}\right) \%$ from the majority group. Assume that $c_{m V}>c_{M V}, c_{m N}=c_{M N}=$ $c_{N}$, and the distribution of $\beta_{i}$ is the same between the two groups. Assume also that condition (B.18) holds. Consider $x_{l}$, a shock in terms of COVID 19 deaths of the locality $l$. We have:

$$
v_{l}^{*}\left(m_{l}, x_{l}\right):=v_{m}^{*}\left(x_{l}\right) m_{l}+v_{M}^{*}\left(x_{l}\right)\left(1-m_{l}\right),
$$

where the equilibrium vaccination rate $v_{i}^{*}\left(x_{l}\right)$ is implicitly defined by (B.8), that is:

$$
c_{i V} v_{i}^{*}-c_{N} x_{l}-\Delta u\left(v_{i}^{*}\right)=0
$$

where $\Delta u\left(v_{i}^{*}\right):=u\left(v_{i}^{*}\right)-u\left(1-v_{i}^{*}\right)$. By differentiating equation (B.20), we obtain:

$$
\frac{\partial v_{i}^{*}}{\partial m_{l}}=v_{m}^{*}-v_{M}^{*}<0,
$$

because $c_{m V}>c_{M V}$. Let us differentiate this last equation. We get:

$$
\frac{\partial^{2} v_{l}^{*}}{\partial x_{l} \partial m_{l}}=\frac{\partial v_{m}^{*}}{\partial x_{l}}-\frac{\partial v_{M}^{*}}{\partial x_{l}}
$$

In order for this derivative to be positive, we need the following condition:

$$
\frac{\partial v_{m}^{*}}{\partial x_{l}}>\frac{\partial v_{M}^{*}}{\partial x_{l}}
$$

that is, the positive effect of deaths in locality $l$ on the vaccination rate of ethnic minorities has to be larger than that on the vaccination rate of the majority group. Using (B.19), condition (B.21) can be written as:

$$
\frac{c_{N}}{c_{m V}-\frac{\partial \Delta u\left(v_{m}^{*}\right)}{\partial v_{m}}}>\frac{c_{N}}{c_{M V}-\frac{\partial \Delta u\left(v_{M}^{*}\right)}{\partial v_{M}}},
$$

which is equivalent to

$$
\frac{\partial \Delta u\left(v_{m}^{*}\right)}{\partial v_{m}}-\frac{\partial \Delta u\left(v_{M}^{*}\right)}{\partial v_{M}}>c_{m V}-c_{M V}
$$

In other words, for a "COVID 19 death shock" to affect more ethnic minorities than the majority group, it has to be that the difference in the marginal benefit of vaccination between the majority and minority group is higher than the difference in the marginal cost of vaccination. One possible explanation that we highlighted in the empirical analysis is that ethnic minorities are more aware of deaths in their community than whites; this would imply that for them the (perceived) marginal 
benefits of vaccination is much higher. If this condition holds, then we obtain the result in column II or III of Table 1 (i.e., an increase of deaths in a community (positively) affects more strongly the vaccination rate of ethnic minorities than that of the majority group). 


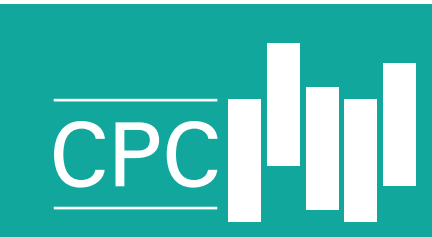

CENTRE FOR POPULATION CHANGE

\section{ESRC Centre for Population Change}

Building 58

Faculty of Social Sciences

University of Southampton

SO17 1BJ

Tel: +44(0)2380592579

Email: cpc@southampton.ac.uk

To subscribe to the CPC newsletter and keep up-to-date with research activity, news and events, please register online: www.cpc.ac.uk/news/newsletter

For our latest research updates you can also follow CPC on Twitter and Facebook:

Y @CPCpopulation

f /CPCpopulation 